\title{
Autonomía moral y legitimidad democrática
}

\author{
Moral Autonomy and Democratic Legitimacy
}

Jan-R. Sieckmann ${ }^{*}$

Recepción y evaluación de propuesta: 10/02/2015.

Aceptación: 17/04/2015.

Recepción y aceptación final: 04/07/2015.

\begin{abstract}
Resumen: La autonomía consiste en la formación de juicios normativos sobre la base de la ponderación de argumentos normativos. Esta concepción permite resolver la paradoja de la autonomía, es decir, cómo los autores de las normas pueden entenderse vinculados por esas mismas normas, explicar la validez objetiva de las normas como resultado de una argumentación autónoma y reconstruir la idea de la democracia como institucionalización de la argumentación autónoma. La argumentación autónoma es un proceso en el que los agentes introducen libremente argumentos normativos y juicios normativos y tratan de llegar a normas comunes a través de un proceso de reflexión intersubjetiva. Cuando de tales procesos resulta una convergencia razonable acerca de la validez de ciertas normas, es legítimo reclamar tales normas como vinculantes. La tarea de la democracia es crear un sistema político que realice las exigencias de la argumentación autónoma.
\end{abstract}

Palabras clave: argumentación autónoma, validez objetiva, democracia.

Abstract: Autonomy consists in the formation of normative judgments, on the basis of weighing normative arguments. This concep-

* Universidad de Erlangen - Universidad de Buenos Aires.

Correo electrónico: jan.sieckmann@fau.de, jansieckmann@yahoo.de

Agradezco a Federico De Fazio, Martín Aldao, Laura Clérico y Juan Iosa por la revisión del trabajo y sus valiosos comentarios. 
tion permits to solve the paradox of autonomy, that is to say, how the authors of the norms can be themselves bounded by those norms, explain the objective validity of the norms as a result of an autonomous argumentation and reconstruct the idea of democracy as an institutionalization of the autonomous argumentation. The autonomous argumentation is a process in which the agents freely introduce normative arguments and normative judgments and try to arrive to common norms through a process of inter subjective reflection. When the result of those processes is a reasonable convergence about the validity of certain norms, it is legitimate to claim that those norms are binding. The task of democracy is to create a political system that performs the requirements of autonomous argumentation.

Keywords: autonomous argumentation, objective validity, democracy.

\section{Introducción}

El derecho, como cualquier otra forma de poder político, requiere contar con una legitimidad ${ }^{1}$ tal que justifique el ejercicio del poder hasta la aplicación de la fuerza ${ }^{2}$. La pregunta entonces es cuál podría ser tal justificación. Podemos constatar que cualquier justificación del poder político debe basarse sobre la idea de la autonomía de los individuos que se ven sujetos a dicho poder. No tenemos otro criterio para legitimar el poder político. En cambio, sostener que existe una justificación del poder político sobre la base de un criterio independiente de la autonomía individual implicaría que algunos individuos pueden es-

1 Originalmente había usado aquí el término "legitimación", entendido como legitimidad que resulta de un proceso de justificación. Sin embargo, como Juan Iosa ha advertido, el término "legitimación" puede entenderse en otro sentido, por lo que en lo que sigue usaré el término "legitimidad". En este segundo sentido la legitimación de una norma equivaldría bien al proceso (no necesariamente racional) por el cual se logra su reconocimiento, la creencia en su legitimidad, bien a la creencia misma, (creencia que puede estar equivocada). (Lo agregado en cursivas pertenece al editor).

2 Véase Kant, I., Metaphysik der Sitten, Einleitung in die Rechtslehre (1797/98), $\S$ E, AB 36, Akademieausgabe (AA), Berlin, 1914, t. 6, pág. 232. También Dworkin, R., Law's Empire, Londres: Fontana, 1986, págs. 93, 190. 
tar sujetos al poder político aunque podrían con razón objetarlo. Pero si alguien pudiera con razón rechazar el poder político, no existiría una justificación o legitimidad de este poder.

En este sentido, filósofos como Rousseau y Kant han destacado que se requiere una legitimidad política compatible con la libertad de los sujetos del poder político. El problema según Rousseau es encontrar una forma de asociación que proteja y defienda con toda la fuerza común a la persona y los bienes de cada asociado y gracias a la cual cada uno se obedezca sólo a sí mismo y permanezca tan libre como antes ${ }^{3}$. Como Kant enfatizó, el poder legislativo debe asignarse a la voluntad unida del pueblo. Como todo el derecho debe provenir de este poder, debe ser imposible que una ley de este poder implique un acto injusto contra alguien. Por el contrario, si un individuo dispusiera sobre otros, siempre sería posible que cometiese actos injustos. Por eso, según Kant, sólo la voluntad unificada de todos, en que cada uno y todos deciden lo mismo para todos y cada uno, puede legislar ${ }^{4}$. Entonces, el problema de la legitimidad del poder legislativo es el de cómo la existencia de las leyes puede resultar compatible con la libertad de cada uno, y cómo, a su vez, es posible dar cuenta de leyes tales que puedan contar con el consentimiento de cada uno y así resultar legítimas.

El consentimiento de los sujetos al poder forma el núcleo de la legitimidad democrática. Pero como el derecho consiste en normas que reclaman ser vinculantes y el poder político implica la competencia o autoridad de tomar decisiones vinculantes para toda la comunidad, no se puede esperar que en un sistema político los individuos queden tan libres como antes, es decir, en un estado natural. Van a perder algo de libertad, y quizás ganar otra forma de libertad. Lo importante es que ello esté justificado por el consentimiento de los individuos afectados.

El problema de la democracia es entonces cómo organizar un sistema tal que el derecho, o al menos la competencia para establecerlo, pueda recibir el consentimiento de cada uno de sus destinatarios. Esta idea, sin embargo, conlleva algunos problemas. ¿Qué tipo de consentimiento es necesario? ¿Por qué el consentimiento es vinculante y no puede ser revocado en cualquier momento? ¿Cómo puede sostenerse la idea de consentimiento frente a las limitaciones propias de cual-

3 Rousseau, J. J., Contrat Social, Amsterdam, 1762, cap. 6.

${ }^{4}$ Kant, op. cit. (n. ${ }^{\circ}$ 2), $\S 46$, AA, t. 6, págs. 313-314. 
quier sistema político real, en particular la necesidad de establecer autoridades que pueden tomar decisiones sin el consentimiento de todos los afectados? Discutiré diversos tipos de consentimiento, una concepción de la autonomía y de la argumentación autónoma que permite justificar normas vinculantes, y el diseño del sistema político desde la perspectiva de la argumentación autónoma.

\section{El criterio del consentimiento}

El criterio del consentimiento puede entenderse de distintas maneras. Una distinción fundamental es entre consentimiento real e ideal. El consentimiento real es un acuerdo empírico. Presupone que actores reales acuerden de hecho sobre cierta solución. El consentimiento ideal presupone que un consenso cumpla ciertas condiciones que garanticen la fuerza justificatoria de este consenso, como un consenso logrado en un discurso ideal. Estas condiciones ideales pueden referirse a los actores, que pueden ser reales o ideales, o al mismo discurso, que puede ser un discurso real o ideal. Actores o discursos ideales se definen por ciertas condiciones ideales. Pero incluso en un discurso real con participantes reales valen ciertas exigencias ideales, como, por ejemplo, la información completa o la imparcialidad completa de sus participantes, que contribuyen a la fuerza justificatoria de tales discursos. Además, existen distintas formas de consentimientos empíricos o ideales. Un consentimiento empírico puede ser no solamente real, sino también hipotético, probable, o posible. Un consentimiento normativo puede ser necesario, hipotético, o posible.

\section{1. Tipos de consenso}

Entre los consensos empíricos podemos distinguir:

- Un consentimiento real existe cuando todos los agentes involucrados aceptan de hecho cierta norma.

- Un consentimiento hipotético existiría cuando se diera un consenso bajo ciertas condiciones. Por ejemplo, se aceptaría un compromiso si los demás hicieran lo mismo. Aunque el consentimiento todavía no es real, se realiza cuando ciertas condiciones empíricas están dadas. 
- Un consentimiento probable existe cuando se puede esperar consenso acerca de cierto tema. Por ejemplo, se puede esperar que cualquier proceso de la argumentación llegaría a un consenso acerca de la protección de la vida humana.

- Un consentimiento posible existe -en sentido empírico- cuando no se pueda excluir que todos acepten cierta solución. Otro sentido - un sentido procedimental-es que todos tengan la oportunidad de consentir. Esto requiere procedimientos en que todos pueden participar, es decir, un sistema democrático.

Por otro lado, entre los consensos ideales puede distinguirse:

- Un consentimiento necesario existe cuando cualquier agente racional debería aceptar cierta norma como resultado de la argumentación.

- En cambio, si no se puede mostrar que cierto consentimiento es imposible, existe un consentimiento posible en sentido ideal ${ }^{5}$.

- El consentimiento hipotético-ideal sería un consenso que se lograría entre agentes razonables bajo condiciones ideales. Por ejemplo, si nadie conociera su posición en la sociedad todos aceptarían principios de máxima libertad y cierta forma de igualdad ${ }^{6}$.

Una forma del consentimiento ideal es el consentimiento razonable, que es un consenso entre agentes razonables, es decir, agentes que juzgan de manera autónoma y racional ${ }^{7}$.

\section{La fuerza justificatoria del consenso}

El problema es si estos distintos tipos de consenso pueden ofrecer una justificación para el poder político. Al respecto, cada una de las alternativas tiene sus debilidades.

${ }^{5}$ Cfr. Alexy, R., Teoría de la argumentación jurídica, Tr. de M. Atienza, Madrid: Centro de Estudios Constitucionales, 1989.

${ }^{6}$ Cfr. Rawls, J., A Theory of Justice, Cambridge: Harvard University Press, 1971.

7 Entonces, razonabilidad se entiende como combinación de autonomía y racionalidad. Véase Sieckmann, J., The Logic of Autonomy, Oxford/Portland (Oregon), Hart Publishing, 2012, 2, n. ${ }^{\circ} 5$. 
El consentimiento empírico-real no es fácil de lograr en los casos problemáticos en los que existen controversias acerca de la solución correcta de la cuestión normativa. Además, sin las restricciones de un discurso ideal, no tiene fuerza justificatoria, porque es posible cometer errores argumentativos, y cualquier resultado podría aparecer como posible en este sentido ${ }^{8}$.

El consentimiento probable no puede presentar una justificación más allá de lo que cada uno piensa, porque cada uno sostiene que su posición es la correcta y espera que todos los demás, en cuanto racionales, acepten está posición, y ninguno puede justificar que justamente su posición vaya a encontrar el consenso de todos.

El consentimiento empírico-hipotético no ofrece una ventaja, pues si se dieran las condiciones para el consentimiento, entonces resultaría un consenso real, y si no, no habría consenso. Y como el consenso empírico-real ya no puede ofrecer una justificación, tampoco la pueden ofrecer formas de consenso empírico que son meramente hipotéticas, probables o posibles.

El consentimiento necesario, por otra parte, presupone que ciertas normas deben ser consentidas o aprobadas necesariamente, en particular, como resultado de un discurso ideal. Pero para mostrar eso, el resultado debe ser calificado como correcto con independencia de la decisión de los agentes involucrados. Entonces el consentimiento parece resultar irrelevante para el resultado, y la autonomía individual queda reemplazada por criterios de validez que son independientes del juicio normativo individual.

El consentimiento hipotético-ideal presentaría una justificación, pero sería una forma de consenso necesario, porque todos los agentes razonables deben aceptar cierta solución en dichas condiciones, lo cual desconocería a la autonomía individual.

8 Durante el proceso de edición de este trabajo Juan Iosa me ha señalado que esta tesis puede ser demasiado fuerte en la medida que niega que un consenso empírico total, como en una democracia directa y por unanimidad, conceda legitimidad a las leyes. De hecho, requerir un discurso ideal es demasiado exigente. Pero algunas exigencias del discurso ideal deben valer para que un consenso empírico tenga fuerza justificatoria. Aunque fuera poco probable, incluso un consenso empírico total podría ser ilegítimo. 
La mera posibilidad de un consenso ideal o el hecho de que una norma sea discursivamente posible ${ }^{9}$, es insuficiente para establecer su validez normativa, ya que varias normas incompatibles entre sí podrían ser objeto de consenso o aprobación dentro de un discurso. Dado que toda norma válida implica la obligación de ser cumplida, y que las normas obligatorias que son incompatibles no pueden ser válidas al mismo tiempo, el criterio de un consenso posible no resulta ser un criterio de validez apropiado.

Además, cuando un consenso es meramente empírico y no necesario, cualquier agente podría cambiar su posición con la consecuencia que ya no habría más consenso. No sería vinculante. En cambio, si un consenso fuera necesario, parece entonces que no quedaría espacio para la autonomía de los individuos. Pero aún así subsiste la alternativa de interpretar el consenso como un contrato. Entonces, el consenso puede ser considerado como vinculante cuando y en la medida en que se pueda justificar qué contratos son vinculantes. La vinculatoriedad de contratos sería una norma objetiva de segundo nivel, que restringiría en algún grado la autonomía individual, aunque dejaría espacio para decisiones individuales. Como toda restricción de la autonomía individual, esta alternativa también requeriría una justificación. Pero no es claro si existe una justificación superior a la autonomía misma. Incluso el principio de la vinculatoriedad de los acuerdos requiere una justificación basada en la idea de autonomía individual. Si un agente razonable pudiera objetar este principio, entonces no estaría justificado.

Entonces queda el problema de cómo es posible una justificación normativa sobre la base de evaluaciones autónomas de todos los agentes involucrados. Esto nos lleva a la pregunta por la autonomía.

\section{La idea de autonomía}

La idea de autonomía ocupa el centro de la filosofía práctica moderna. Literalmente, autonomía significa auto-legislación ${ }^{10}$, esto es,

${ }^{9}$ Cfr. Alexy, op. cit. n. ${ }^{\circ} 5$.

${ }^{10}$ Sobre la interpretación de la autonomía como auto-legislación, véase Bittner, R., Moralisches Gebot oder Autonomie?, Freiburg/München, Alber, 1983, 120; Reath, R., Agency and Autonomy in Kant's Moral Theory. Selected Essays, Oxford: Clarendon Press, 2006, pág. 92.; y sobre la autonomía 
establecer la validez de una norma mediante las propias decisiones normativas de sus destinatarios: los agentes autónomos determinan por sí mismos qué norma es válida para ellos ${ }^{11}$. En términos de Kant, la voluntad de un agente racional no sólo se encuentra sujeta a la ley moral, sino que además tiene que darse esa ley a sí mismo (selbstgesetzgebend) y justo por eso es que queda sujeto a la ley ${ }^{12}$. La idea de autonomía como auto-legislación, sin embargo, parece tener una estructura paradójica ${ }^{13}$. Entendida como auto-legislación, la autonomía parece exigir que la validez de las normas dependa de su reconocimiento, es decir, de que sus destinatarios, en cuanto agentes autónomos, reconozcan que esas normas son válidas. Pero, por otra parte, las normas pretenden vincular u obligar a sus destinatarios, y ¿cómo puede una persona estar vinculada por normas cuya validez depende de que ella misma, como destinataria, las reconozca como válidas? Si, por el contrario, las normas son válidas con independencia del juicio individual, ¿cómo puede sostenerse que los individuos son autónomos? Si ellos no determinan qué normas son válidas, no se están "auto-legislando".

en general, Kaufmann, M., Rechtsphilosophie, Freiburg/München, Alber, 1996 o Schneewind, J., The Invention of Autonomy, New York: Cambridge University Press, 1998.

${ }^{11}$ La autonomía moral no siempre es interpretada como autolegislación. Pueden distinguirse la autolegislación y el juicio propio como dos concepciones de la autonomía moral. Véase Iosa, J., "Concepciones de la autonomía", Filosofia Social e Teoría do Direito, 2010, 60; id., "La estructura del conflicto entre autoridad y autonomía", Analisi e diritto, 2011, págs. 47-48.

${ }^{12}$ Kant, I., Grundlegung zur Metaphysik der Sitten, Akademieausgabe (AA), Berlin, 1911, t. 4, pág. 431. Trad. en Castellano: "La voluntad, de esta suerte, no está sometida exclusivamente a la ley, sino que lo es de la manera que puede ser considerada como legislándose a si propia, y por eso mismo, y sólo por eso, sometida a la ley (de la que ella misma puede considerarse autora". Fundamentación de la metafisica de las costumbres, trad. Por Manuel García Morente, Madrid, Espasa Calpe, 1980. (disponible en http://www. cervantesvirtual.com).

${ }^{13}$ Cfr. Wood, A., Kantian Ethics, Cambridge, Cambridge University. Press, 2008, págs. 109-110; Reath, A., op. cit., n. ${ }^{\circ}$ 10, pág. 93; Baumann, P., Die Autonomie der Person, Paderborn, Mentis, 2001, pág. 11; Bittner, R., op. cit. (n. $\left.{ }^{\circ} 10\right)$, pág. 118 y ss.; o Wolff, R.P., In Defense of Anarchism, Berkeley, University of California Press, 1973, págs. 180-81. 


\section{1. La paradoja de la autonomía}

El dilema que plantea la idea de autonomía surge porque la auto-legislación implica que la validez de una norma depende de la voluntad, es decir, de un acto de reconocimiento ${ }^{14}$ por parte de la persona a quien ésta se dirige. La validez debe entenderse en sentido normativo, es decir, la validez de una norma implica que ésta se debe aplicar y cumplir. Desde luego, esa elección debe ser razonable, o sea, debe cumplir con los requisitos de una decisión razonable; pero no puede derivarse de normas preexistentes que hayan sido establecidas sobre la base de la moral o la razón práctica. Ahora bien, si una norma es válida solo a causa de la decisión de sus destinatarios, cabría decir entonces que no puede ser vinculante para ellos, y por lo tanto tampoco ser válida en un sentido normativo. La paradoja de la autonomía surge, entonces, del hecho de que la decisión autónoma, por una parte, debe ser auto-determinada y no puede derivarse de normas preexistentes, mientras que, por la otra, pretende establecer una norma válida, lo que presupone que hay razones normativas por las cuales la norma en cuestión debe ser considerada válida y, por ende, vinculante para sus destinatarios. Así pues, las decisiones autónomas no pueden ser por completo libres: tienen que estar limitadas normativamente. El primer requisito hace depender la validez de las normas de la aceptación individual mientras que el segundo implica que dicha propiedad es, en algún sentido, independiente de la aceptación de sus destinatarios. ¿Cómo escapar de los cuernos de este dilema?

Parece que la discusión filosófica no ha encontrado todavía una respuesta plausible ${ }^{15}$, y que se ocupa, más bien, de otros fenómenos relacionados con, aunque distintos de, la autonomía en cuanto auto-legislación.

${ }^{14}$ Es decir, reconocimiento de la validez, no de la verdad. Se debe entenderlo como aceptación de la validez de una norma, no como acto epistémico.

${ }^{15}$ No obstante algunas sugerencias sobre cómo resolver este problema, cfr., por ejemplo, Paton, H. J., The Categorical Imperative. A Study in Kant's Moral Philosophy, $3^{\circ}$ ed., London: Hutchinson, 1958, 182f.; Beck, L.W., $A$ Commentary on Kant's Critique of Practical Reason, Chicago/London, Chicago University Press, 1960, pág. 123. 


\section{III.1.1. Concepciones de la autonomía como autolegislación}

Una interpretación usual de la autonomía la define como la capacidad para reconocer la ley moral y actuar conforme a ella; tal concepción, atribuida a $\mathrm{Kant}^{16}$, mantiene la idea de validez objetiva de las normas morales ${ }^{17}$. Podría ser denominada "concepción realista" de la autonomía. Esto, sin embargo, no cuadra con la idea de autonomía como auto-legislación, ya que presupone la existencia de una ley moral que ya es válida antes y con independencia de que sea reconocida o aceptada por agentes autónomos. Si se asume la tesis de que las normas son válidas no porque los individuos las acepten como tales, sino en virtud de algún criterio predeterminado, se termina asumiendo una teoría que socava la autonomía individual.

La autonomía podría residir aquí, desde el punto de vista de la "concepción realista" en el hecho de que, si bien una persona razonable adoptará necesariamente la ley moral, para estar sujeto a esta ley tiene que comprenderse a sí mismo como un ser razonable ${ }^{18}$. O sea, no es que las normas existan en un mundo independiente de nuestra mente, sino que se les atribuye validez. Sin embargo, ya está determinado a qué normas se debe atribuir validez. Así se combina una concepción realista con un elemento del constructivismo. Pero subsiste el problema de la idea de la auto-legislación, es decir, cómo puede una persona entenderse a sí misma obligada o vinculada por normas que son válidas como resultado de su propia decisión. Y en cualquier caso, esta concepción de la "autonomía sin elección", donde la ley moral es la única opción para elegir, presenta como mucho un supuesto extremo, y no da cuenta del hecho de que amplias partes de

${ }^{16}$ Cfr. Kant, I., op. cit., n. ${ }^{\circ} 12$, AA, t. 4, págs. 428, 431, 432, 440, 461; id., Kritik der praktischen Vernunft, AA, Berlin 1913, t. 5, pág. 31. También Wildt, A., Autonomie und Anerkennung. Hegels Moralitätskritik im Lichte seiner FichteRezeption, Stuttgart, Klett-Cotta, 1982, pág. 173; Baumann, op. cit., n. ${ }^{\circ} 13$, pág. 154.

${ }^{17}$ Cfr. Wood, op. cit., n. ${ }^{\circ}$ 13, 112; Kain, P., "Self legislation in Kant's Moral Philosophy", Archiv für Geschichte der Philosophie, 83, 2004, pág. 257 y ss.

${ }^{18}$ Cfr. Kant, op. cit. (1996a: 4: 450). Juan Iosa ha advertido que en las traducciones de Kant al castellano se usa "racional", no "razonable". Sin embargo, el término "racional" puede ser entendido de manera limitada, que no incluye todo lo que implica ser razonable. 
la moral se ocupan de la elección razonable, es decir, de la decisión libre basada en argumentos normativos y limitada por demandas de racionalidad ${ }^{19}$.

Si uno, por el contrario, intenta preservar la autonomía garantizando que la ley moral $u$ otros principios vinculantes para los agentes autónomos tengan carácter meramente formal y dejen margen para la decisión individual, surge el problema de cómo podría considerarse que la decisión se encuentra normativamente limitada. En especial, si los agentes eligen máximas sujetas a la restricción que marca el imperativo categórico ${ }^{20}$, resulta que hay varias máximas que pueden superar el test. Pero entonces este criterio no ofrece una razón para creer que la máxima que elige el agente es vinculante para él, pues igualmente podría haber elegido una de esas otras máximas.

Otra propuesta es la que afirma que un agente es libre si primero elige una máxima por la que queda después vinculado ${ }^{21}$. Esto, sin embargo, significaría que se excluye una deliberación ulterior y que la decisión inicial es autoritativa. En consecuencia, la obligatoriedad deriva de la autoridad y no del razonamiento autónomo. Además, según esta interpretación, uno perdería su propia autonomía al hacer uso de ella, lo que resulta muy poco satisfactorio. Nada puede impedir a un agente autónomo cuestionar sus propias decisiones y efectuar una nueva elección. La decisión anterior, como tal, no afecta a la decisión posterior.

Una interpretación procedimental del imperativo categórico, entendido como proceso deliberativo más que como criterio estático de validez ${ }^{22}$, tampoco resuelve la cuestión. Sigue siendo un problema tanto que el proceso deliberativo pueda tener más de un resultado como que conduzca solo a un único resultado. Si son posibles resultados diferentes, parece que ninguno de ellos se puede considerar vinculante; y si solo es posible un único resultado, entonces no puede haber elección autónoma.

${ }^{19}$ Sobre la concepción de razonabilidad como combinación de autonomía y racionalidad véase Sieckmann, op. cit., n. ${ }^{\circ} 7,2$, n. $^{\circ} 5$.

${ }^{20}$ Cfr. Paton, op. cit., n. ${ }^{\circ} 15$, pág. 183.

${ }^{21}$ Brandom, R., Making it Explicit. Reasoning, Representing, and Discursive Commitment, Cambridge (Mass.)/Londres, Harvard University Press, 1994, pág. 50 y ss.

${ }^{22}$ Reath, op. cit., n. ${ }^{\circ} 10$, pág. 104. 
Tampoco la teoría del discurso ${ }^{23}$ puede explicar cómo los agentes autónomos pueden quedar vinculados por el consenso alcanzado discursivamente. Aunque existiera consenso, en tanto que nada impide a los agentes autónomos revocar su consentimiento, éste no sería vinculante. Por otro lado, es cierto que la teoría del discurso no usa solo el criterio del consenso, sino trata de desarrollar argumentos pragmático-trascendentales que intentan revelar presupuestos necesarios de la praxis o práctica comunicativa ${ }^{24}$ que cualquiera ha de aceptar necesariamente al tomar parte en la comunicación, y estos argumentos dan a entender que algunos de esos presupuestos implican derechos que deben ser reconocidos de manera necesaria. Tales derechos, en la medida en que refuerzan el razonamiento autónomo, encajan con la idea de autonomía y pueden justificarse como presupuestos de esta idea o, menos ambiciosamente, como instrumentos del razonamiento autónomo. Sin embargo, los argumentos pragmático-trascendentales no resultan ya compatibles con el razonamiento autónomo si pretenden introducir restricciones sustantivas sobre lo que los agentes autónomos pueden defender, reclamar o aceptar como normas válidas. Un individuo autónomo no tiene por qué aceptar las reglas de la práctica comunicativa si puede proponer una alternativa. Por lo tanto, la existencia de una praxis comunicativa y sus presupuestos no pueden limitar el razonamiento autónomo.

Desde otro punto de vista, pueden distinguirse tres tipos de concepciones de la autonomía como autolegislación ${ }^{25}$ : el voluntarismo, el constructivismo y el realismo. El voluntarismo asume que el deber es constituido por actos de voluntad legislativos. El realismo asume que la ley moral está inscripta en la estructura normativa de la voluntad de un agente racional. El constructivismo entiende a los deberes

${ }^{23}$ Cfr. Habermas, J., Between Facts and Norms, Cambridge (Mass.), MIT Press, 1996 (orig.: Faktizität und Geltung, 4 ed., Frankfurt a.M., Suhrkamp, 1994); id., The Inclusion of the Other, Cambridge (Mass.), MIT Press, 1998 (orig.: Die Einbeziehung des Anderen, Frankfurt a.M., Suhrkamp, 1996).

${ }^{24}$ Cfr. Apel, K.O., Transformation der Philosophie, t. 2, Frankfurt/aM., Suhrkamp, 1973; Habermas, J., Erläuterungen zur Diskursethik, Frankfurt/ aM., Suhrkamp, 1991; Alexy, R., "Diskurstheorie und Menschenrechte", en Alexy, R., Recht, Vernunft, Diskurs, Frankfurt a.M., Suhrkamp, 1995, págs. 127-164

${ }^{25}$ Siguiendo a Iosa, op. cit., n. $\left.{ }^{\circ} 11\right)$ págs. 69-70. 
morales como resultado de un proceso de deliberación. Cada una de estas concepciones destaca algo importante para una concepción de autonomía: el elemento volitivo, la necesidad de construir normas a través de la deliberación, la pretensión de que las normas existen con cierta independencia de lo que cada uno crea y no son solo creaciones arbitrarias. Sin embargo, ninguna de estas concepciones parece adecuada: el voluntarismo no puede explicar cómo los actos voluntarios pueden ser vinculantes.

El realismo no deja la posibilidad de elegir y así no permite la autolegislación. El constructivismo no puede explicar cómo llegar a un resultado vinculante cuando la deliberación permite distintos resultados igualmente posibles y no puede explicar tampoco cómo es posible la autolegislación cuando sólo cabe un único resultado.

\section{1.2. Concepciones que no tratan de autolegislación}

En vista de que la filosofía práctica no encuentra una solución satisfactoria para la paradoja de la autonomía, algunos autores han sostenido que la idea de autonomía individual es una simple metáfora ${ }^{26}$, o que la noción de autonomía tiene sentido solo si se la concibe como autonomía política ${ }^{27}$. Así, la discusión acerca de la autonomía a menudo no se ocupa de la auto-legislación ${ }^{28}$, sino de la autodeterminación ${ }^{29}$; de la autonomía personal ${ }^{30}$; de la facultad de ordenarse hacer a sí mismo

${ }^{26}$ Patzig, G., "Philosophische Bemerkungen zum Begriff der Autonomie", en: Patzig, G., Gesammelte Schriften I: Grundlagen der Ethik, Göttingen, Wallstein Verlag, 1994, pág. 174 y ss.

${ }^{27}$ Baumann, op. cit., n. ${ }^{\circ} 13$, pág. 11.

${ }^{28}$ Excepciones son Wood, op. cit., $\mathrm{n}^{\circ} .13$, pág. 106 y ss.; Reath, op. cit., n. ${ }^{\circ} 10$, pág. 92 y ss.; Kain, op. cit., n. ${ }^{\circ} 17$, pág. 257 y ss. Cfr. también Nino, C. S., The Ethics of Human Rights, Oxford, Oxford University Press, 1991, págs. 137-138; Nagl-Docetal, H., "Autonomie zwischen Selbstbestimmung und Selbstgesetzgebung", en: Pauer-Studer, H. y Nagl-Docetal, H. (eds), Freiheit, Gleichheit, Autonomie, Viena/Berlín, Oldenbourg/Akademie Verlag, 2003, págs. 296-326.

${ }^{29}$ Hurley, S., Natural Reasons, Oxford/Nueva York, Oxford University Press, 1989, pág. 314 ss.; Mele, A.R., Autonomous Agents. From Self-Control to Autonomy, Oxford, Oxford Univ. Press, 1995.

${ }^{30} \mathrm{Raz}$, J., The Morality of Freedom, Oxford, Clarendon, 1986; Spector, H., Autonomy and Rights, Oxford, Oxford University Press, 1994; Mele, op. cit., n. ${ }^{\circ} 29$. 
lo que se piensa que sería una buena idea hacer ${ }^{31}$; de la capacidad de abandonar la comunidad moral o de no seguir la ley moral ${ }^{32}$; o, en fin, del problema del libre albedrío. Sin embargo, ninguna de estas concepciones ofrece una explicación de la idea de auto-legislación. Por el contrario, deben distinguirse de ella.

La posibilidad y existencia del libre albedrío es un tema central en las discusiones filosóficas sobre autonomía. La cuestión es si las decisiones individuales pueden estar libres de predeterminaciones causales o empíricas ${ }^{33}$. No obstante, este enfoque no proporciona una concepción de la auto-legislación individual, sino que se ocupa más bien de un problema diferente: cómo conjugar la existencia de decisiones individuales con las concepciones empíricas del mundo, si son o no son causales, y de investigaciones de psicología cognitiva que ofrecen explicaciones empíricas de cómo funciona la mente humana ${ }^{34}$.

La noción de auto-legislación tiene que distinguirse también de la autodeterminación y de la autonomía personal y privada. La autodeterminación puede entenderse, de forma negativa, como lo contrario de la heteronomía ${ }^{35}$, es decir, como el derecho a juzgar y decidir por uno mismo sin estar sujeto a la influencia de otros; o bien puede entenderse positivamente, en el sentido de la autonomía personal, que incluye, por un lado, la capacidad y, por otro, el derecho a llevar una vida auto-determinada. Esto comprende la decisión de conducirse moralmente o no, pero no la determinación de qué normas resultan moralmente válidas. La autonomía privada significa que uno tiene competencia para regular por sí mismo sus propios asuntos. Pero, una vez más, nada de esto implica que la validez de las normas sea establecida por sus mismos destinatarios; cuando menos, todos estos enfoques son compatibles con la idea de unas normas preexistentes que son válidas con independencia del juicio individual; o bien, si se entiende que incluyen una elección, no pueden mostrar por qué la norma elegida tendría que reputarse vinculante. En definitiva, tam-

\footnotetext{
${ }^{31}$ Korsgaard, C., "The Authority of Reflection", en Koorsgaard, C.M., The Sources of Normativity, Cambridge, Cambridge University Press, 1996, pág. 107.

${ }^{32}$ Tugendhat, E., Vorlesungen über Ethik, Frankfurt a.M., Suhrkamp, 1993, pág. 89.

${ }^{33}$ Cfr. Patzig, op. cit., n. ${ }^{\circ}$ 26, 176; Schneewind, op. cit., n. ${ }^{\circ}$ 10, págs. 515, 520.

${ }^{34}$ Cfr. Korsgaard, op. cit., n. ${ }^{\circ} 31$, págs. 96-97.

${ }^{35}$ Cfr. Schneewind, op. cit., n. ${ }^{\circ} 10$, pág. 4.
} 
poco estas nociones permiten explicar la idea de autonomía como auto-legislación.

La noción de autonomía pública o política, en cambio, sí incluye la de auto-legislación, por cuanto se refiere a la determinación de normas colectivamemente vinculantes. Pero tropieza, no obstante, con el problema de cómo es posible la auto-legislación. Sin una concepción de la auto-legislación individual, no está claro cómo pueda operar la auto-legislación colectiva. No funciona solo, en la realidad, sobre la base del consentimiento individual, sino que requiere decisiones colectivas que pueden ser mayoritarias o de ciertos órganos políticos. Si la autonomía pública es así, que los individuos pueden quedar sujetos a la decisión de la mayoría o a la decisión de los órganos políticos, esta sujeción, de nuevo, requiere una justificación referida al juicio individual y no explica la idea de auto-legislación.

En suma, ninguna de las concepciones mencionadas ofrece un tratamiento adecuado de la autonomía individual. Así que, voy a sugerir una concepción del razonamiento autónomo que define la autonomía como una estructura conforme a la cual un juicio normativo se forma sobre la base de la ponderación de argumentos normativos. Una tesis central de este enfoque es precisamente que la estructura de la ponderación de argumentos normativos proporciona una solución a la paradoja de la autonomía tal como acabo de plantearla: la autonomía consiste, entonces, en la ponderación de argumentos normativos.

\section{2. La lógica de la autonomía}

La cuestión central que abordaré ahora es la justificación de normas basada en la idea de autonomía ${ }^{36}$. Esta justificación supone un "razonamiento autónomo", o sea, un razonamiento hecho por agentes autónomos del que resultan decisiones con respecto a qué norma es definitivamente válida $\mathrm{y}$, por tanto, vinculante $\mathrm{u}$ obligatoria para dichos agentes. El razonamiento autónomo comienza con agentes que plantean demandas o pretensiones normativas y efectúan juicios nor-

${ }^{36}$ Véase también: Sieckmann, J., "The Concept of Autonomy", en GizbertStudnicki, T./Stelmach, J. (eds), Law and Legal Cultures in the 21st Century, Diversity and Unity, Cracovia, Oficina/Kluwers, 2007, págs. 149-170; Sieckmann, The Logic of Autonomy, op. cit., n. ${ }^{\circ} 7$. 
mativos en cuanto a qué norma debe ser aceptada como válida en relación con esas pretensiones. Este razonamiento reconoce el derecho de cada agente autónomo a plantear pretensiones y formular juicios normativos, pero también reconoce que ninguno de ellos puede determinar, por medio de su propio juicio normativo individual, si esta o aquella norma es definitivamente vinculante para otros agentes. Las normas definitivamente vinculantes solo pueden determinarse mediante enunciados o proposiciones que tengan en cuenta los diversos juicios de los agentes autónomos ("tesis de la interdependencia"), lo cual requiere un proceso de reflexión intersubjetivo dirigido a determinar qué norma debe considerarse vinculante, sobre todo ante casos de desacuerdo razonable entre agentes autónomos. Por tanto, los enunciados normativos tienen que basarse en algo más que en los juicios normativos individuales. A su vez, el razonamiento autónomo implica que ninguna norma puede considerarse definitivamente válida con independencia de las pretensiones o juicios normativos de los agentes autónomos.

Por ejemplo, en el caso de las expresiones ofensivas, entran en conflicto los intereses en la protección del honor personal y los intereses en la libre expresión. Los agentes plantearán sus pretensiones normativas basadas en esos intereses, como la pretensión de que las expresiones ofensivas deben ser prohibidas, o la de que cualquier expresión, incluso las ofensivas, deben ser permitidas. El conflicto entre ambas pretensiones requiere de una ponderación, sobre cuya base los agentes efectuarán juicios normativos. Estos juicios darán prioridad a una de las pretensiones en conflicto, por más que condicionalmente suela entenderse, por ejemplo, que cualquier forma de expresión, incluso las insultantes, deben permitirse mientras tengan una causa legítima y no persigan meramente humillar a una persona. No obstante, distintos agentes pueden aducir juicios normativos diferentes, y ninguno/a de ellos/as puede pretender determinar la situación normativa por sí solo/a. De ahí que se necesite una segunda ponderación que incluya una reflexión intersubjetiva sobre qué norma debe ser aceptada como definitivamente válida en casos de pretensiones y juicios normativos contrapuestos. Esa reflexión intersubjetiva puede lograr la aceptación común de una norma particular como definitivamente válida. Si lo logra, uno puede sostener que dicha norma está objetivamente justificada y, en el supuesto de que se requiera una norma colectivamente 
vinculante para todos, que dicha norma es objetivamente vinculante para sus destinatarios.

\section{2.1. Cómo no entender la autonomía}

El problema de la idea de autonomía como auto-legislación es cómo puede uno estar vinculado por una norma cuya validez depende del juicio de uno mismo. Si uno está en posición de decidir qué norma es válida, obviamente esa norma no puede vincular la decisión que uno tome. Y como uno es libre de cambiar su propia visión normativa, tampoco puede quedar vinculado por una decisión previa de considerar válida una norma. La dicotomía entre elección y obligatoriedad parece ineludible mientras concibamos la validez de las normas como algo parecido a su existencia objetiva. $\mathrm{O}$ bien una norma existe objetivamente, o sea, al margen del reconocimiento por parte de sus destinatarios, y entonces no hay autonomía, o bien la norma no existe objetivamente, en cuyo caso no puede ser vinculante para las personas a quienes se dirige. ¿Hay alguna alternativa a esta dicotomía? Para ser capaces de encontrarla, debemos evitar ciertas asunciones comunes.

(1) No debemos presuponer que las normas morales existen independientemente de su reconocimiento por parte de agentes autónomos. Por consiguiente, en el plano de la argumentación normativa debemos evitar un compromiso con el realismo moral.

El razonamiento autónomo tan solo garantiza la validez de normas al margen del consentimiento individual en la medida en que estas constituyen un marco para el razonamiento moral. Esto incluye, formalmente, requisitos de racionalidad práctica como, por ejemplo, ofrecer una justificación para las pretensiones normativas, tratar los casos iguales de igual manera o procurar cumplir las exigencias normativas en la mayor medida posible. E incluye también, sustantivamente, argumentos normativos basados en las pretensiones legítimas de los agentes autónomos. Estos argumentos ya son válidos y por tanto vinculan a otros agentes, si bien solo sea como argumentos, por cuanto es un agente autónomo quien ha planteado una de esas pretensiones. Los demás agentes deben aceptar tal pretensión como un argumento válido que debe ser ponderado con argumentos contrapuestos. 
Más allá de los requisitos de racionalidad y argumentación normativa, sólo se puede pretender que las normas definitivas sean vinculantes si, además de ser resultado del razonamiento autónomo colectivo, producen una norma colectivamente vinculante. Sin embargo, la validez de estas normas depende de la aceptación de los agentes autónomos, y eso contradice el realismo moral.

(2) Debemos rechazar la idea de que los argumentos normativos a favor de una norma concreta implican pretensiones sobre su corrección moral en sentido cognitivo.

Los agentes autónomos deben presentar argumentos normativos acerca de qué norma debería considerarse válida, pero no pueden establecer individualmente normas vinculantes para otros agentes autónomos. Por lo tanto, no pueden pretender conocer por sí mismos lo que sea moralmente correcto. De otra parte, no necesitan justificar con razones cognitivas sus demandas basadas en intereses y sus correspondientes argumentos normativos. Antes bien, la autonomía incluye la competencia normativa para alegar esos argumentos, y con ello se establece la obligación para otros agentes de prestarles el debido respeto en su razonamiento.

(3) Debemos evitar tanto una interpretación descriptiva como una interpretación prescriptiva de los enunciados de normas que son usados como argumentos normativos ${ }^{37}$.

De acuerdo con una interpretación descriptiva, los enunciados normativos expresan proposiciones normativas. Si esas proposiciones son verdaderamente normativas, y no meras aserciones de hechos empíricos relativos a una particular norma ${ }^{38}$, entonces incluyen una descripción de una norma $(\mathrm{N})$ y una adscripción de validez a dicha nor$\mathrm{ma}$, con lo que se pretende que su contenido normativo debe efectiva-

${ }^{37}$ Para estas interpretaciones, cfr. Stuhlmann-Laeisz, R., Das Sein-Sollen-Problem, Stuttgart/Bad Cannstatt, Frommann-holzboog, 1983, 23; Alchourrón, C.E. y Bulygin, E., Normative Systems, Vienna, Springer, 1971, pág. 121; v. Wright, G.H., Norm and Action, Londres/Nueva York, Routledge \& Kegan Paul, 1963, pág. 132; Kamp, G., Logik und Deontik, Paderborn, Mentis, 2001, pág. 19.

${ }^{38} \mathrm{La}$ otra interpretación, que se encuentra en v. Wright, op. cit. (n. $\left.{ }^{\circ} 37\right), 132$, y en Alchourrón y Bulygin, op. cit., n. ${ }^{\circ}$ 37, 121, incluye aserciones descriptivas acerca de hechos empíricos, no de normas. 
mente ser aplicado y observado. Sin embargo, los agentes autónomos, en el curso de su argumentación, no pueden plantear razonablemente esta pretensión, porque no pueden presuponer la existencia de una norma sin considerar las visiones normativas de otros agentes autónomos. En sus argumentos, solo pueden plantear pretensiones acerca de qué norma debe ser aceptada como válida.

Por otra parte, también debemos evitar una interpretación prescriptiva de los enunciados de normas usados como argumentos normativos, porque los agentes autónomos no están en posición de establecer prescripciones frente a otros agentes autónomos. Pueden plantear pretensiones o demandas normativas sobre otros agentes, pero la medida en que tales pretensiones hayan de ser aceptadas como normas definitivamente válidas, es decir, deban ser efectivamente aplicadas y observadas, no depende del juicio de un único agente, sino que puede determinarse solo sobre la base de los juicios normativos de todos los agentes autónomos implicados.

En suma, al analizar el razonamiento autónomo, el primer paso es dejar de lado las discusiones habituales sobre realismo moral, sobre cognitivismo y sobre el carácter descriptivo o prescriptivo de los enunciados normativos. Estas discusiones no tienen mucho sentido sin una comprensión adecuada de la estructura de la justificación normativa. Lo que hace falta, en su lugar, es analizar qué sucede cuando los agentes autónomos aducen argumentos normativos en un intento de establecer normas como válidas y vinculantes.

\section{2.2. La estructura del razonamiento autónomo}

El punto de partida del razonamiento autónomo son las pretensiones o las demandas basadas en intereses, que constituyen argumentos normativos que exigen que cierta norma sea aceptada como definitivamente válida; un proceso del que resultan juicios normativos individuales y, eventualmente, aserciones normativas de normas definitivamente válidas y, por tanto, vinculantes. La peculiar estructura de los argumentos normativos, así como la de su ponderación por agentes autónomos, determina la estructura del razonamiento autónomo o, dicho en forma abreviada, la "lógica de la autonomía". Y es esto lo que hace posible entender el concepto de autonomía como auto-legislación. 
El núcleo del razonamiento autónomo consiste en la ponderación de argumentos normativos basados en las pretensiones de los agentes autónomos ${ }^{39}$. Los argumentos normativos exigen un resultado concreto de esta ponderación, un resultado plasmado en un juicio normativo que establece que cierta norma es definitivamente válida y, por tanto, ha de ser en efecto aplicada y observada. Cuando ocurre un conflicto que no se encuentra resuelto por una regla establecida los argumentos en conflicto deben ponderarse según su importancia en las circunstancias del caso concreto para establecer una prioridad entre ellos, la cual determina una norma con validez definitiva. La validez definitiva significa que una norma es resultado de una ponderación de todos los argumentos e información relevantes. Esto es, marca la transición de la argumentación a la aserción de una norma que guía la acción. Más precisamente, el juicio normativo que proviene de la ponderación puede incluir dos elementos: primero, que una determinada norma debe ser definitivamente válida; $\mathrm{y}$, segundo, que la norma es definitivamente valida. Al segundo elemento cabe llamarlo "proposición normativa".

El ejemplo de las expresiones ofensivas esbozado antes presenta cuatro características de la ponderación autónoma.

(1) El resultado de la ponderación no puede inferirse a partir de normas preexistentes, sino que debe ser establecido mediante un juicio autónomo.

Si hubiera que decidir el caso de acuerdo con normas preestablecidas, no quedaría espacio para la autonomía. Cabría objetar que los conflictos pueden resolverse con reglas ya establecidas. Por ejemplo, los tribunales podrían haber establecido una regla por la cual la libertad de expresión prevalece sobre derechos contrapuestos siempre que la expresión sea una contribución adecuada a la discusión de los asuntos públicos; y entonces la argumentación podría tratar acerca de lo que haya que entender por "adecuado" en este contexto. Sin embargo, la respuesta a esta cuestión no queda establecida ya por dicha regla; y aunque así fuese, la regla podría cuestionarse ante nuevos casos. Por tanto, seguiría habiendo un problema de ponderación. De ahí que el

${ }^{39}$ Cfr. Sieckmann, J., "Legal System and Practical Reason", Ratio Juris 5, 1992, págs. 288-307, 296; id., "Autonome Abwägung", ARSP 90, 2004, pág. 66 ; id., op. cit., n. ${ }^{\circ} 36$, pág. 149 ; id., op. cit., n. ${ }^{\circ} 7$, págs. 13,85 y ss. 
razonamiento autónomo sea opuesto al razonamiento interpretativo, en la medida en que el objetivo de la interpretación es determinar el significado existente de una norma dada. También se opone a las concepciones que consideran la ponderación de argumentos como alguna forma de cálculo. De nuevo, si hubiese suficiente información disponible para efectuar dicho cálculo, tampoco quedaría margen para una decisión o elección autónoma. El razonamiento autónomo es compatible con las reglas de la ponderación correcta, pero presupone que tales reglas no determinan el resultado de la ponderación. Es importante, pues, distinguir el razonamiento autónomo tanto respecto de la interpretación como del cálculo.

(2) Los argumentos normativos son resultado de pretensiones que plantean los agentes autónomos basándose en sus intereses.

El esquema de tales pretensiones es que uno quiere que una norma sea válida y, por tanto, exige o pretende que debe ser válida. Cualquier pretensión basada en intereses es legítima, y constituye un argumento normativo válido, sencillamente, porque un agente autónomo la ha planteado. No se requiere ninguna justificación adiciona ${ }^{40}$. La validez como argumento normativo implica que todos los demás agentes están obligados a dar la debida consideración a este argumento en su razonamiento ${ }^{41}$. No obstante, hay límites a la validez de tales argumentos: los argumentos normativos pueden exigir solo aquellos resultados de la ponderación que sean posibles; y como los resultados dependen de los juicios de agentes autónomos, solo son posibles los que sean razonablemente aceptables para todos los demás agentes. Por tanto, rige aquí un criterio de universabilidad. En general, uno no puede negar la relevancia de los intereses de otros agentes autónomos para una argumentación; y tampoco puede transformar un interés en un argumento normativo cuando dicho interés persigue, por su propio contenido, una injerencia injustificada en los intereses de otros agen-

${ }^{40}$ Cfr. en contra Nino, C. S., The Constitution of Deliberative Democracy, New Haven/London, Yale University Press, 1996, pág. 165.

${ }^{41}$ Entonces, implica un poder normativo en el sentido de Hohfeld, esto es: dar la posición de crear obligaciones argumentativas para otros agentes. Cfr. Hohfeld, W. N., Fundamental Legal Conceptions as Applied in Legal Reasoning and Other Legal Essays, New Haven, Yale University Press, 1923, pág. 23 y ss. 
tes. Por ejemplo, los intereses en el asesinato, la violación o el robo no pueden constituir argumentos normativos válidos que otros agentes tengan que considerar en su deliberación. Por tanto, las pretensiones basadas en los intereses de los agentes autónomos constituyen argumentos normativos solo si pueden tenerse por legítimas.

(3) Los argumentos normativos incluyen exigencias de validez, esto es, demandan que una norma concreta sea aceptada como definitivamente válida.

El quid de la argumentación autónoma es qué norma debería aceptarse como resultado de la argumentación. Por consiguiente, los argumentos normativos incluyen exigencias para que una norma concreta sea aceptada como resultado de la argumentación; o sea, incluyen exigencias de que una norma concreta sea definitivamente válida. Empleando "O" para expresar el operador deóntico "deber", "VAL ${ }_{\mathrm{DEF}}$ " como predicado para "... es válido definitivamente", y " $\mathrm{N}_{\mathrm{i}}$ " como variable para las instancias particulares de normas, los argumentos normativos presentan esta estructura:

$\mathrm{O} \mathrm{VAL}_{\mathrm{DEF}} \mathrm{N}_{\mathrm{i}}$.

Es importante que tales exigencias de validez no se interpreten como proposiciones o enunciados normativos. Pues para contar como argumento dentro de una ponderación de argumentos en conflicto, un argumento normativo ha de reconocer la validez de los argumentos contrapuestos al tiempo que mantiene su fuerza argumentativa en la situación de conflicto. Esto es, los argumentos normativos no solo deben ser objeto de ponderación, sino que deben contar también como razones dentro de la ponderación. Esto no sería posible si los argumentos normativos tuviesen el carácter de enunciados o proposiciones, ya que los enunciados normativos demandan que se cumpla la norma enunciada y, por tanto, precluyen la consideración de las exigencias normativas contrapuestas. Un enunciado y la proposición que incorpora se dirigen a denotar un hecho. Pero si fuese un hecho que uno debe cumplir una norma, ninguna norma contrapuesta podría ser reconocida como válida al mismo tiempo. Por el contrario, las exigencias de validez mantienen su validez como argumentos a favor de un resultado concreto incluso en una situación de conflicto con otros argumentos normativos. 
Queda el problema de cómo construir argumentos con estas características. La idea es que los argumentos normativos incluyen mandatos de validez reiterados. Es decir, cada mandato de validez de cierto nivel está apoyado por otro de un nivel superior, que exige reconocer la validez del primero. Es decir, un argumento normativo consiste en una cadena reiterada de argumentos:
$\mathrm{OVAL}_{\text {DEF }} \mathrm{N}_{\mathrm{i}}$.
$\mathrm{OVAL}_{\text {DEF }} \mathrm{OVAL}_{\text {DEF }} \mathrm{N}_{\mathrm{i}}$.
$\mathrm{OVAL}_{\text {DEF }} \mathrm{OVAL} \mathrm{VAEF}_{\mathrm{DEF}} \mathrm{OVAL}_{\mathrm{DEF}} \mathrm{N}_{\mathrm{i}}$.

etc.

La estructura de argumentos normativos puede anotarse como

$$
\text { ... O VAL } \mathrm{VEF}_{\mathrm{D}} \mathrm{N}_{\mathrm{i}}
$$

Esta estructura lógica de los argumentos normativos tiene implicancias interesantes ${ }^{42}$. Aquí interesa que permite explicar la idea de la autonomía moral como autolegislación. El primer paso es la pretensión de corrección normativa que se sigue de la estructura de los argumentos normativos.

(4) La estructura de los mandatos de validez implica que los juicios normativos incluyen la pretensión de que el resultado establecido es normativamente necesario.

De acuerdo con esto, los agentes autónomos plantean la pretensión de la necesidad normativa (NN) de sus juicios:

(NN) Cualquiera que sea la norma que un agente, a resultas de la ponderación de argumentos normativos contrapuestos, proponga como definitivamente válida, debe pretender que la validez de dicha norma viene exigida por el argumento más fuerte.

Esta pretensión de necesidad normativa es crucial para la estructura de la autonomía. La autonomía se define como una estructura para la toma de decisiones normativas, esto es, una estructura para efectuar juicios normativos basados en la ponderación de argumentos normativos. La estructura de esta ponderación puede explicar los dos aspectos del juicio autónomo: elegir libremente una norma y al mismo tiempo 
quedar vinculado por la propia decisión. Por tanto, este juicio puede entenderse como un acto de auto-legislación.

Por una parte, una característica esencial de la ponderación de argumentos normativos es que la prevalencia de un argumento sobre los demás no puede deducirse de criterios objetivos, sino que requiere de un juicio normativo. Por consiguiente, el agente podría haber tomado una decisión diferente; y en este sentido su juicio es libre.

Por otra parte, esta ponderación establece una norma válida, y en este sentido constituye un caso de legislación. Un acto legislativo requiere, primero, atribuir validez a una norma que, en segundo lugar, debe tenerse por normativamente válida por cuanto la norma debe ser aplicada y observada. En tercer lugar, el acto ha de implicar que los/as destinatarios/as de la norma deben aceptarla como válida. Estas son características inherentes a la legislación: un legislador no puede decir que, aunque establece una norma válida, cualquiera es libre de seguirla o no; y tampoco puede pretender que alguien deba seguir esa norma aunque no haya ninguna razón por la que debiera aceptarla como válida. Expresiones semejantes desbaratarían el propósito mismo de la legislación. Por lo tanto, la marca de un acto legislativo es la atribución de validez a una norma junto con la pretensión de que sus destinatarios/as deben aceptarla como válida.

Los juicios basados en la ponderación de argumentos normativos poseen estos rasgos o características. Atribuyen validez definitiva a una norma, con lo que pretenden que debe ser aplicada y observada y que se debe aceptar como válida. El primer rasgo se sigue de la función pragmática, en tanto guía de la acción, de las proposiciones normativas. El segundo rasgo deriva de la estructura de los argumentos normativos en cuanto requisitos de validez de una norma. Cualquier juicio que resulte de la ponderación de argumentos normativos, aunque sea libre y no esté determinado por criterios preestablecidos, tiene que reflejar la pretensión de que viene exigido por el argumento normativo más fuerte. Por tanto, cualquiera que sea el juicio, está vinculado por argumentos normativos que exigen que este resultado de la ponderación sea el elegido. Debido a esta estructura, el juicio autónomo no supone una decisión arbitraria, como escoger entre té o café. Al contrario: cualquiera que sea el juicio, viene exigido por el argumento normativo más fuerte $\mathrm{y}$, por tanto, ha de entenderse como una decisión exigida por razones normativas. 
Por ejemplo, si uno decide que las expresiones ofensivas sean permitidas, esto no es solo porque uno lo quiere así, sino porque se sigue del principio de libertad de expresión, el cual se considera como el argumento más fuerte en la ponderación.

Esto convierte la estructura lógica de los argumentos normativos, en cuanto requisitos de validez de una determinada norma, en algo crucial para la estructura de la autonomía. La estructura de la toma de decisiones autónoma es precisamente lo que caracteriza la estructura de la moral autónoma. El requisito conceptual de que una elección moral sea libre al tiempo que está vinculada por estándares morales queda satisfecho por la estructura de la ponderación de argumentos normativos. Por tanto, la ponderación de argumentos normativos se presenta como la esencia de la autonomía moral. Y esta estructura no es privativa de la moral, sino que opera en todos los tipos de ponderación de argumentos normativos: los juicios jurídicos basados en esta clase de justificación son, igualmente, juicios autónomos -así, por ejemplo, las decisiones judiciales basadas en la ponderación de principios jurídicos, las decisiones administrativas discrecionales vinculadas por principios jurídicos y las decisiones legislativas vinculada por principios constitucionales-. Todos estos tipos de decisiones presentan una estructura común por cuanto no son meras decisiones, sino juicios basados en la ponderación de argumentos normativos.

\section{Definiciones de autonomía}

Ahora podemos definir el concepto de autonomía más precisamen$\mathrm{te}^{43}$. La idea general de autonomía como auto-legislación puede formularse como sigue:

$\mathrm{DF}_{\mathrm{A}}$ "Autonomía" significa establecer la validez definitiva de una norma mediante los juicios normativos de sus propios/as destinatarios/as.

Esta idea incluye tanto la autonomía individual como la colectiva. De un lado, la autonomía incluye la idea de que los agentes autónomos pueden juzgar por sí solos lo que es obligatorio, lo que está prohibido y lo que está permitido. De otro lado, un colectivo de agentes

${ }^{43}$ Véase Sieckmann, op. cit., n. ${ }^{\circ} 7$, pág. 17 y ss. 
autónomos puede efectuar juicios para establecer normas que vinculen a todos (normas colectivamente vinculantes, normas vinculantes comunes).

La autonomía individual puede definirse como:

$\mathrm{DF}_{\mathrm{AI}}$ "Autonomía individual" significa establecer la validez definitiva de una norma mediante el juicio normativo individual de uno/a mismo/a.

Esta concepción de la autonomía individual tropieza, sin embargo, con un problema. Dado que los agentes autónomos no pueden, mediante su solo juicio individual, establecer normas definitivas que vinculen a otros agentes autónomos, las normas vinculantes únicamente pueden establecerse mediante una argumentación en la que todos esos agentes puedan participar, y donde los intereses y argumentos de todos reciban la debida consideración. No obstante, los agentes autónomos pueden efectuar juicios normativos individuales basados en la ponderación de todos los argumentos relevantes. Tales juicios son definitivamente válidos en el sentido de que son juicios "todas las cosas consideradas" (all-things-considered); o sea, no quedan ya argumentos que pudiesen -a juicio del agente- alterar el resultado de la ponderación. La autonomía incluye la idea de que uno es capaz de efectuar estos juicios normativos individuales.

Así pues, hay que distinguir entre la validez definitiva procedimental y la validez definitiva sustantiva. La primera significa que se han considerado todos los argumentos, de modo que los agentes autónomos pueden efectuar juicios normativos individuales respecto a qué norma deben tener por definitivamente válida. La segunda significa que una norma es válida de manera definitiva en el sentido de que es efectivamente vinculante para sus destinatarios/as. Y esto puede establecerse solo mediante un proceso discursivo intersubjetivo.

Por consiguiente, la autonomía individual, tal como se ha definido antes, tiene que entenderse como el establecimiento de la validez definitiva de una norma en sentido procedimental, en conexión con la pretensión de que esa norma debe ser aceptada, aplicada y observada como resultado del procedimiento. Como vimos, esta pretensión normativa tropieza, sin embargo, con la autonomía de otros agentes. Por tanto, en cuanto a la cuestión de la obligatoriedad, los juicios autónomos individuales pueden determinar solo qué normas considera un agente vinculantes para él/ella mismo/a. Esto, desde luego, no ha 
de interpretarse como que un agente autónomo establece solo normas para sí mismo/a. Los juicios normativos pretenden establecer una norma que debe ser aplicada y observada por todos sus destinatarios/as. Limitar la autonomía al establecimiento de normas solo para uno/a mismo/a no cuadraría con el carácter general o universal de la justificación normativa. Si esta justificación ha de ser válida, no puede referirse a individuos singulares. Una restricción a la validez de las normas establecidas autónomamente solo puede provenir de la autonomía de los demás agentes. El respeto a su autonomía requiere que se limite la pretensión de obligatoriedad que se efectúa para las normas que un agente singular sostiene como definitivamente válidas. Por lo que hace a los demás agentes, tal pretensión puede efectuarse solo como válida en principio, es decir, como un argumento normativo que los demás han de tener en cuenta.

De acuerdo con esto, si resultase que es posible establecer la validez definitiva de una norma en un sentido pleno o sustantivo, solo una comunidad de agentes autónomos podría hacerlo. Una norma es válida para tal comunidad si sus miembros consideran que la correspondiente norma es definitivamente válida para ellos y ellas. Esta dimensión colectiva puede denominarse también "autonomía política", que cabe definir como sigue:

$\mathrm{DF}_{\mathrm{AP}}$ "Autonomía política" significa establecer normas que sean definitivamente válidas y vinculantes mediante los juicios normativos de sus propios/as destinatarios/as.

Por lo tanto, en el sentido aquí definido, la autonomía política intenta establecer normas vinculantes comunes (o colectivamente vinculantes) mediante los juicios normativos de sus respectivos/as destinatarios/as. Se podría concluir que la autonomía como auto-legislación puede definirse solo en el plano o nivel colectivo. Pero esto sería ir demasiado lejos. La autonomía individual es esencial para cualquier concepción de la autonomía, ya que todos los agentes individuales pueden aducir argumentos normativos y efectuar juicios normativos. El problema crucial es cómo conectar el plano individual con el colectivo. A continuación procuraré ofrecer una solución a este problema mediante un análisis que reconstruye la autonomía política sobre la base de juicios individuales autónomos. Este análisis retoma alguno de los puntos arriba desarrollados. 
Un punto importante de este análisis es que considera la autonomía como una característica del juicio normativo o de la toma de decisiones justificables. En cuanto resultado de la ponderación de argumentos normativos, un juicio normativo establece que una norma es definitivamente válida. Por tanto, un agente tiene autonomía si está en posición de tomar una decisión normativa basada en la ponderación de argumentos normativos. Tal decisión se encuentra vinculada por argumentos, pero no está determinada, respecto al resultado, por criterios preestablecidos. Cabría pensar en un caso extremo en el que hubiese solo un único argumento relevante, con lo que el resultado estaría determinado; pero, aun así, se requiere una decisión para transformar la pretensión normativa en un juicio normativo. Se puede entonces definir la autonomía de un agente (AA) como sigue:

$\mathrm{DF}_{\mathrm{AA}} \mathrm{Un}$ agente tiene autonomía si está en posición de tomar una decisión normativa vinculada por argumentos normativos.

La autonomía puede definirse también como una estructura decisoria específica. En contraste con la autonomía entendida como atributo de un agente, ahora no se trata ya de una propiedad o atributo de alguien, sino de una característica de una situación en la que ha de tomarse una decisión normativa. Este parece ser el sentido más elemental de la autonomía, si la concebimos abstrayéndola de los agentes implicados y nos centramos en la estructura de la argumentación. Esta estructura se caracteriza por la ponderación de argumentos normativos, es decir, autonomía como balanceo (AB):

$\mathrm{DF}_{\mathrm{AB}}$ Existe autonomía si una decisión normativa ha de tomarse mediante la ponderación de argumentos normativos.

De nuevo, como caso extremo, podría suceder que se aplicara tan solo un único argumento relevante. Pero esto parece ser una mera posibilidad teórica. En la realidad, el razonamiento práctico siempre se ocupa de argumentos contrapuestos, y de ahí que se pueda definir la autonomía como la ponderación de argumentos normativos.

La noción de autonomía como ponderación de argumentos normativos constituye una concepción formal de la autonomía, que hay que diferenciar claramente del valor de la autonomía ${ }^{44}$. Y hay que distin-

${ }^{44}$ En cambio, Hurley, op. cit., n. ${ }^{\circ} 29$, pág. 328 , considera a la autonomía como un valor que puede entrar en conflicto con otros valores. 
guirla también de la autonomía entendida como una capacidad y de la autonomía en el sentido de un derecho a decidir autónomamente.

La autonomía como capacidad requiere que un agente sea capaz de tomar decisiones autónomas, esto es, que sea consciente de que debe establecer prioridades entre pretensiones o argumentos normativos contrapuestos, y que sea capaz de ponderar estos argumentos correctamente. Aquí, la corrección depende de requisitos formales de racionalidad respecto a la ponderación de argumentos normativos, como, por ejemplo, la consistencia, la conclusividad, la coherencia, la corrección empírica, la universabilidad y la reflexión intersubjectiva. Según esto, un agente autónomo es capaz de efectuar juicios normativos basados en la ponderación de argumentos normativos conforme a los requisitos formales de racionalidad.

El derecho a tomar decisiones autónomamente incluye diversas cuestiones. Ante todo, incluye el derecho a efectuar argumentos y juicios normativos. Lo que interesa aquí especialmente es, no obstante, que este derecho implica a su vez una obligación, de parte de cualquier agente autónomo, de considerar en su razonamiento los argumentos y juicios normativos aducidos por todos los demás agentes autónomos. Luego las normas definitivamente válidas no pueden establecerse sin considerar los argumentos normativos de todos y cada uno de los agentes autónomos. Dado que los agentes individuales pueden por sí mismos cumplir esta exigencia, ninguno/a de ellos/as está sujeto a los juicios normativos del resto, con lo que todos tienen igual condición. Este derecho a no estar sujeto a los juicios normativos de otros agentes, sin embargo, parece poner en duda que mediante un razonamiento autónomo puedan establecerse normas vinculantes.

\section{La argumentación autónoma}

Queda el problema de explicar la estructura de la argumentación autónoma y las condiciones del establecimiento de normas vinculantes a través de la argumentación autónoma, para después esbozar cúales serían las instituciones adecuadas para establecerlas. ¿Cómo es posible establecer normas objetivamente válidas sobre la base de la argumentación autónoma?

El objetivo de la argumentación normativa es establecer normas vinculantes y, en este sentido, objetivamente válidas. La fundamenta- 
ción de normas objetivas debe depender del consenso de los agentes autónomos. Como vimos, no hay otro fundamento para la validez de las normas que la aceptación de su validez, por parte de agentes autónomos, como consecuencia de una argumentación racional. Los reclamos meramente subjetivos no pueden considerarse normas vinculantes, pues cualquier agente autónomo puede tener sus propios reclamos. Sin embargo, no es clara la relación entre validez y consenso. Para evitar que la idea de la fundamentación en el consenso de agentes autónomos quede vacía, no se debe exigir un consenso real de todos. Debe ser una forma más débil, de orientación al consenso. Primero podemos constatar que la autonomía individual excluye pretender la validez de una norma sin considerar los argumentos y opiniones de otros agentes autónomos. Además, la meta de una argumentación autónoma debe ser el consenso de los agentes autónomos. Una concepción de fundamentación que se apoya en la razón de sujetos autónomos debe orientarse -al menos como idea regulativa-por el criterio de que una norma sea reconocida por todo agente razonable ${ }^{45}$. Para explicar esta idea sirve un ejemplo.

\section{1. Un ejemplo: la prohibición de fumar}

Como ejemplo de una argumentación autónoma podemos considerar la justificación de una prohibición de fumar en lugares públicos. Puede considerarse como una cuestión moral o jurídica. Desde el punto de vista moral el problema es si se puede fundamentar una norma reclamando que no se debe fumar en lugares públicos. Desde el punto de vista jurídico el problema es si se debe prohibir el fumar en lugares públicos. Los argumentos en ambos casos son básicamente los mismos.

Entran en conflicto, por un lado, los intereses de los fumadores de ejercer su libertad y otros motivos, como disfrutar el efecto del tabaco o mejorar su capacidad de trabajar. Por otro lado, para los demás puede ser una molestia o aún un riesgo para su salud. Todos los intereses constituyen argumentos normativos, que implican exigencias sobre cuál sea la norma definitivamente válida en cierta comunidad.

${ }^{45}$ Por agente razonable entiendo un agente autónomo que respeta las exigencias de la argumentación racional. 
Los argumentos en conflicto deben ser balanceados para determinar una prioridad entre ellos y, por tanto, una norma común. Acá es relevante la importancia que tengan los argumentos en conflicto y en qué grado estén afectados los intereses que fundamentan estos argumentos ${ }^{46}$. Pueden existir diferencias en el peso y el grado de afectación de los intereses que favorecen claramente uno de los lados. Sin embargo, en tanto que la ponderación lleva a un juicio autónomo, diversas opiniones pueden resultar de tal ponderación.

Entonces será necesario una ponderación de segundo orden acerca de cúal de las opiniones en conflicto debe tener prioridad. Todos los agentes autónomos deben hacer tales ponderaciones desde su perspectiva. En cuanto que la solución depende de la opinión de todos los agentes por igual, deben dar la misma consideración a las opiniones de cada uno. Esto significa un proceso de reflexión intersubjetiva ${ }^{47}$. Si no llegan a un consenso, deben repetir el proceso hasta que la continuación del proceso no prometa cambios de opiniones. Este proceso de argumentación autónoma puede dar resultados, aunque esto no será necesariamente así.

\section{2. Elementos de la argumentación autónoma}

Este ejemplo permite distinguir varios elementos de la argumentación autónoma. La argumentación autónoma consiste en:

(1) la formación de argumentos normativos basados en intereses y opiniones de agentes autónomos;

(2) la ponderación de argumentos normativos para establecer normas definitivas que provienen de las pretensiones de agentes autónomos respecto de cuáles normas deben ser reconocidas como definitivamente válidas;

${ }^{46}$ Sobre la estructura de tales ponderaciones véase Sieckmann, op. cit., n. ${ }^{\circ} 7$, pág. 85 y ss.; Alexy, R., Teoría de los derechos fundamentales, 3.ed., Madrid, 2008, pág. 130 y ss., pág. 520 y ss.

${ }^{47}$ Sieckmann, J., "On the Tension Between Moral Autonomy and Rational Justification", Ratio Juris, 16, 2003, págs. 105-122; id., op. cit., n. ${ }^{\circ}$ 7, págs. $82,117$. 
(3) la reflexión intersubjetiva respecto de las diversas concepciones normativas de los agentes autónomos, considerando la situación de conflicto de las diversas opiniones y evaluando cuál sea la norma adecuada para ésta situación. Deben ser juicios autónomos, aunque tomando un punto de vista imparcial, que considere todas las concepciones normativas relevantes cómo igualmente válidas e importantes. El resultado serán exigencias equilibradas y juicios autónomos acerca de lo que sean las normas definitivamente válidas.

\section{2.1. La formación de argumentos normativos}

Los argumentos normativos se constituyen en base a la competen$\mathrm{cia}^{48}$ de los sujetos autónomos para incluir tales argumentos en una argumentación ${ }^{49}$. Como el resultado de una argumentación es dependiente de la aprobación de sujetos autónomos, deberá reconocerse el derecho de estos sujetos a presentar argumentos que serán considerados en las reflexiones de otros participantes de la argumentación. Negar tal derecho implicaría que no sería posible llegar a un resultado que los agentes autónomos aceptarían como vinculante. Autonomía individual es, en este sentido, una competencia para hacer válidas las exigencias en una argumentación y con ello, obligar a otros a considerar tales exigencias en sus ponderaciones; a su vez requiere considerar los argumentos de los otros agentes en las propias ponderaciones. Es importante observar que no es necesaria una fundamentación sustancial de los argumentos presentados para que sean válidos como argumentos normativos ${ }^{50}$.

Con ello, la constitución de los argumentos normativos depende de un criterio determinable empíricamente, a saber, qué argumentos

${ }^{48}$ Competencia se entiende, como traté de explicar en apartados anteriores, en forma análoga al poder jurídico en sentido Hohfeldiano. Cfr. Hohfeld, op. cit., $\mathrm{n}^{\circ} 38$.

${ }^{49}$ Sieckmann, J., "Cultural Pluralism and the Idea of Human Rights", en: A. Soeteman (coord.), Pluralism and Law, Dordrecht, Kluwer, 2001, pág. 240; id., op. cit., n. ${ }^{\circ} 7$, págs. 14 y 70 .

${ }^{50}$ En cambio, Nino, C. S., Ética y derechos humanos. Un ensayo de fundamentación, Barcelona, Ariel, 1989, pág. 268, parece exigir una justificación sustancial. Véase también Nino, op. cit., n. ${ }^{\circ} 28$. 
son presentados en realidad por los sujetos autónomos. Sin embargo, también es necesaria una evaluación según criterios de racionalidad; más precisamente, condiciones de racionalidad formal. Así, han de excluirse argumentos inconsistentes o que contengan premisas empíricamente refutables, como también exigencias no universalizables que no pueden ser aceptadas por otros sujetos autónomos. Además la alegación de intereses y de sus pesos está sujeta a exigencias de coherencia. Se debe excluir que un individuo califique cada uno de sus intereses de importancia sobresaliente y exija la correspondiente consideración. Partiendo de la exigencia de mantener la aprobación de cada uno de los participantes de la argumentación, la totalidad de los intereses de cada uno debe ser tratada con igual importancia. Pues de otro modo, aquéllos cuyos intereses son postergados en su totalidad, podrían razonablemente negar la aprobación del resultado de la argumentación.

\section{2.2. La ponderación de argumentos normativos}

La ponderación de argumentos normativos debe cumplir las condiciones de una argumentación racional. Son necesarias la consideración de todos los argumentos relevantes, la consistencia de la fundamentación y del resultado ponderativo, la corrección de las premisas empíricas empleadas y la determinación de los grados de satisfacción o restricción, así como la coherencia de la ponderación con respecto al peso relativo de argumentos ${ }^{51}$. Tratándose de la ponderación de intereses individuales, se exigirá también la igual consideración de las concepciones coherentes de cada sujeto autónomo acerca de sus intereses. Mediante estos criterios se pueden desechar algunos juicios ponderativos. Otros se pueden valorar en virtud del grado o medida en el que cumplen estos criterios ${ }^{52}$.

Sin embargo, esta forma de fundamentación no es suficiente para demostrar la validez objetiva de una proposición sobre la validez definitiva de una norma, puesto que es posible que diversos juicios ponderativos satisfagan los criterios de crítica racional y por consiguiente, sean justificables en igual medida. Por supuesto cada uno piensa que

${ }^{51}$ Sieckmann, op. cit., n. ${ }^{\circ} 7$, pág. 93 y ss.

${ }^{52}$ Véase Sieckmann, op. cit., n. ${ }^{\circ} 47$. 
su ponderación es correcta. Sin embargo, ninguno puede reclamar que el resultado al que ha arribado es objetivamente válido en el sentido de que todos los agentes razonables necesariamente tienen que aceptarlo. Lo que resulta de la ponderación individual son pretensiones (como exigencias) de agentes autónomos de cuáles normas deben ser reconocidas como válidas definitivamente. Pero estas exigencias pueden encontrarse con exigencias de la misma legitimidad. Por tanto, la ponderación individual todavía no permite constatar que una norma es objetivamente válida.

\section{2.3. Reflexión intersubjetiva}

El objetivo de la argumentación a favor de la validez objetiva de una norma es demostrar que todo agente razonable debe reconocer como vinculante una norma determinada. La pregunta es si se puede fundamentar tal obligatoriedad de las normas en virtud de las ponderaciones. Como los juicios individuales no pueden determinar normas válidas para otros agentes autónomos, la divergencia de las convicciones normativas basadas en ponderaciones racionales requiere la reflexión intersubjetiva de estas distintas posiciones. Esto es, cada agente debe incluir en sus reflexiones los juicios divergentes de otros para determinar qué norma debe valer definitivamente. Puede servir como criterio para estos juicios el de la fuerza de la aceptación racional ${ }^{53}$.

En caso que no haya un consenso sobre el asunto en discusión, es necesario un cambio en el enfoque inicial. En vez de preguntar, en un primer nivel, por la solución objetiva correcta, se debe preguntar, en un meta-nivel, qué norma, en la situación de concurrencia de diversas concepciones, debe ser reconocida como obligatoria.

La reflexión intersubjetiva puede conducir a una convergencia de diversas concepciones. De tratarse de la pregunta acerca de si debe estar prohibido fumar en edificios públicos, en caso de haber una mayoría para una determinada opinión, se les podrían adherir a estos otros -que sean de otra opinión-, sobre la cuestión de qué norma debería valer como obligatoria. $\mathrm{O}$ podría haber en el primer nivel una mayoría contra la prohibición de fumar, mas algunos, considerando las exigencias de otros de una prohibición de fumar, pueden llegar a la concepción de 
que tal prohibición debe establecerse. De darse cambios de opiniones en el nivel próximo más alto de la argumentación, ha de preguntarse nuevamente, con respecto a los cambios de opinión, qué norma debería reconocerse como obligatoria, y así sucesivamente. De este modo, se puede dar una convergencia de concepciones normativas.

Sin embargo, no es seguro que la reflexión intersubjetiva conduzca a una convergencia. Lo contrario también es posible. No es suficiente para establecer validez objetiva. Con todo, es posible que la reflexión intersubjetiva en la argumentación autónoma llegue a constatar la validez objetiva de una norma.

\section{3. La validez objetiva}

Más allá de formar juicios individuales reflexivos sobre la base de la argumentación autónoma, es posible hacer aserciones objetivas con respecto a los resultados de la argumentación autónoma. El criterio puede ser el de la convergencia razonable ${ }^{54}$.

La convergencia razonable acerca de la validez de una norma, lograda por argumentación racional, es decir, autónoma y reflexiva, justifica sostener la norma como vinculante, incluso para sus opositores. Sin embargo, la validez objetiva de una norma no implica que cada agente autónomo deba aceptarla como válida. Los agentes autónomos deben tomar en cuenta los criterios de la convergencia razonable y de la fuerza de la aceptación racional en su deliberación acerca de qué norma debe aceptarse como definitivamente válida en la situación del conflicto de opiniones. Pero aun habiendo cumplido esta exigencia, su autonomía les permite sostener una concepción normativa opuesta.

Por ejemplo, el hecho de que la argumentación acerca de la permisibilidad de fumar resulta en que cada vez más agentes sostienen que no se debe fumar en lugares públicos y, entonces, existe una convergencia razonable acerca de este tema, no obliga a aceptar esta posición. Los agentes autónomos deben considerar este hecho en sus deliberaciones, pero pueden sostener que no hay argumento suficiente para negar la libertad de fumar.

Finalmente, queda el problema de que la convergencia de concepciones no excluye una oposición racional. Aun cuando se vislumbre

${ }^{54}$ Véase Sieckmann, op. cit., n. ${ }^{\circ} 47$; id., op. cit., n. ${ }^{\circ}$ 7, 12, 83 y 116. 
una tendencia hacia un consenso sobre una determinada concepción, un sujeto autónomo puede llegar a un resultado divergente. Aun si se impone la concepción de que la prohibición de fumar en lugares públicos debe ser aceptada, un fumador (o un no fumador) podría seguir con la opinión de que la situación de necesidad de los fumadores adictos a (o amantes de) la nicotina o el principio de libertad no han sido suficientemente considerados. Entonces queda la posibilidad de la divergencia de la reflexión subjetiva y una tendencia objetivamente constatable hacia un consenso.

Sin embargo, en este caso de divergencia es legítimo reclamar para la norma apoyada por el criterio de convergencia razonable el carácter de vinculante, y así objetivamente válida, incluso para sus opositores, en tanto es necesario tener una norma común. Sin embargo, las perspectivas de los partidarios y de los oponentes de una norma difieren en este punto.

Los partidarios de una norma respaldada por convergencia razonable pretenderán que esta norma es vinculante para ellos y que, desde su punto de vista, es válida con independencia de los juicios de agentes individuales. Aunque alguien cambiase de opinión, ello no afectaría a la validez de la norma respaldada por convergencia. Por lo tanto, cabe sostener la siguiente tesis acerca de la pretensión de obligatoriedad (PO):

(PO)Los destinatarios de normas que apoyan una norma respaldada por convergencia razonable pretenderán que esta norma es vinculante para ellos.

La convergencia razonable, sin embargo, es insuficiente para sustentar la pretensión de que una norma es vinculante para los oponentes que rechazan la validez de la misma. Por ejemplo, restringir la libertad de expresión para proteger frente a los insultos contra las creencias religiosas puede estar respaldado por convergencia razonable; pero así y todo, alguien podría sostener razonablemente, después de considerar todos los argumentos y las diferentes visiones normativas sobre el tema, que la ponderación correcta entre la libre expresión y la protección de la religión debería incluso permitir tales insultos. Para quien sostenga esto, el hecho de la convergencia razonable constituirá solo un argumento en sus deliberaciones. Pero si, en contra de este argumento, niega razonablemente la validez definitiva de la norma, la convergencia razonable tampoco podrá servir como argumento 
para que la norma que rechaza sea vinculante para él. Una pretensión semejante no lograría respetar su autonomía.

La pretensión de que una norma es vinculante incluso para quienes no la aceptan requiere, entonces, una justificación adicional. Cabría mostrar que los agentes deben aceptar la convergencia razonable como criterio último de validez, y que deben por tanto restringir su autonomía individual. Esto puede resultar apropiado con respecto a la validez jurídica, pues el derecho no es un asunto de autonomía individual, sino que pretende proporcionar normas colectivamente vinculantes. Aquí, sin embargo, no continuaré por esta línea de argumentación.

En lugar de eso, cabría defender que quienes se oponen a una norma, aunque rechacen su obligatoriedad, deben aceptar razonablemente la corrección de la pretensión de obligatoriedad que elevan los partidarios de dicha norma. La condición de convergencia razonable, si bien excluye la obligatoriedad de las normas que compiten con las normas apoyadas, no establece la obligatoriedad de estas, ya que puede darse el caso de que ninguna de las normas en conflicto pueda revindicarse como vinculante. Pero esta posibilidad queda excluida si se necesita una norma vinculante común ${ }^{55}$, en cuyo caso se debe establecer una norma que sea obligatoria para todos los agentes. Esta norma debe ser la norma que recibe más apoyo en una argumentación racional. No se puede reclamar que una norma con menos apoyo racional se impone por sobre una norma con más apoyo racional. Además, el criterio de la convergencia razonable garantiza que no puede haber una norma alternativa con más o igual apoyo racional. Por eso, incluso aquellos que rechazan una norma respaldada por convergencia razonable tienen que reconocer la corrección de la pretensión de que dicha norma es vinculante. De aquí resulta la siguiente tesis acerca de la pretensión de la obligatoriedad de una norma (PON):

(PON) Se puede pretender correctamente que una norma sea vinculante incluso para quienes no la aceptan si se satisfacen dos condiciones:

${ }^{55}$ Esto se corresponde con la tesis liberal de que las normas no pueden justificarse únicamente sobre la base de concepciones de la vida buena sino sólo cuando es necesario para regular conflictos entre individuos. 
(1) que la norma esté respaldada por convergencia razonable; y

(2) que sea necesario tener una norma vinculante común ${ }^{56}$.

Esta pretensión de obligatoriedad se sigue de un razonamiento correcto, de modo que está justificada objetivamente en sentido estricto $^{57}$. Cualquiera debe reconocer la corrección de la pretensión de que la norma respaldada por convergencia razonable es vinculante si se necesita una norma común. Conviene notar, con todo, que la corrección de la pretensión de obligatoriedad no equivale a la objetividad en el sentido de que cualquier agente razonable deba aceptar la norma como vinculante. Los que se oponen a ella pueden seguir haciéndolo y criticar el juicio generalmente aceptado con la pretensión de que una norma rival sea reconocida como válida ${ }^{58}$. Sólo se debe reconocer la legitimidad de la pretensión de obligatoriedad basada sobre una convergencia razonable en la situación de que una norma vinculante en común parece necesaria ${ }^{59}$.

${ }^{56} \mathrm{La}$ necesidad de tener una norma vinculante común es un problema normativo que, como el de la validez de una norma, puede discutirse. Este tipo de discusión puede encontrarse, por ejemplo, a propósito de la demarcación de los asuntos públicos y privados

${ }^{57}$ La justificabilidad o corrección de una pretensión de obligatoriedad significa que se cumplen todos los requisitos de la argumentación racional. Equivale a una pretensión de posibilidad discursiva (cf. Alexy, op. cit., n. ${ }^{\circ}$ 5) o defendibilidad de la pretensión de validez objetiva, la cual, con todo, no es análoga a la verdad.

${ }^{58}$ Esto cuadra con la tesis de que uno no puede demostrar la validez de una ley penal ante un delincuente de conciencia o por convicción, por más que pueda obligársele a aceptar la condena.

${ }^{59}$ Por ejemplo, se puede constatar una convergencia razonable acerca de la prioridad de la libertad de expresión frente a la protección de derecho de la personalidad en casos en que la expresión sea ofensiva pero contribuye de manera adecuada al discurso acerca de un asunto de interés público. Un crítico podría seguir sosteniendo que la protección al derecho de la personalidad merece prioridad incluso en estos casos. Sin embargo, debe reconocer que es objetivamente legítimo dar prioridad a la libertad de expresión y aplicar y enforzar las normas que resultan de esta prioridad. 


\section{La institucionalización de la argumentación autónoma}

La legitimidad política debe basarse en el consentimiento de los agentes autónomos que se ven sujetos al poder político. La concepción de la autonomía esbozada explica cómo es posible la legitimidad de las normas y decisiones normativas vinculantes. Se requiere una argumentación autónoma en que los agentes introduzcan sus intereses, reclamos y posiciones normativas en forma de argumentos y aserciones normativas en un proceso de reflexión intersubjetiva. Esto puede referirse a las normas mismas o a la competencia para establecer normas vinculantes, es decir, a la autoridad legislativa.

Las debilidades de la argumentación en torno a los problemas para realizar un discurso ideal, de su capacidad de encontrar soluciones normativas y de garantizar su cumplimiento, requieren reconocer una autoridad política que pueda tomar decisiones vinculantes ${ }^{60}$. Sin embargo, la necesidad de reconocer una autoridad política no debe llevar a la conclusión que la legitimidad política se deriva solo de la justificación de tal autoridad. La autoridad de tomar decisiones vinculantes no libera de las exigencias de la argumentación autónoma. Es un instrumento para realizarla, no para reemplazarla.

Entonces, la legitimación democrática requiere tomar decisiones políticas de manera que estas puedan ser justificadas por un proceso de argumentación autónoma. En consecuencia, el sistema político debe ser organizado para realizar tales procesos de argumentación. Entonces, ¿cómo se deben diseñar las instituciones del sistema político más adecuadas para establecer una legitimación argumentativa?

Parece obvio que debe ser un sistema democrático. Una primera opción es la democracia directa ${ }^{61}$. Promete el nivel de participación más alto. Sin embargo, y más allá de los problemas para realizarla, no ofrece instrumentos para cumplir con las exigencias de la argumenta-

${ }^{60}$ Acerca de la necesidad de las autoridades y del derecho véase, por ejemplo, Alexy, R., "Ley fundamental y teoría del discurso", en id., La construcción de los derechos fundamentales, Buenos Aires, Ad Hoc, 2010, pág. 80 y ss.

${ }^{61}$ Para Wolff, op. cit., n. ${ }^{\circ} 13$, la democracia directa permite combinar autonomía y autoridad. Sin embargo, esto vale solo cuando se acepte el principio de unanimidad, no el principio de la mayoría. Para un análisis de las tesis de Wolff ver Iosa, J., "Wolff entre autoridad y autonomía", Cuadernos de Filosofia del Derecho, 33, 2010, págs. 518 y 550 y ss. 
ción autónoma. Por ejemplo, no exige una decisión racional de los votantes y no tiene recursos para compensar distorsiones en el proceso político que impiden la consideración imparcial de todos los intereses involucrados. Entonces no es un sistema ideal desde la perspectiva de la idea de la autonomía.

El sistema de la democracia representativa tampoco puede considerarse como el óptimo con respecto a la realización de la deliberación ${ }^{62}$. Restringe la participación directa de todos los agentes autónomos. Por otro lado, permite realizar exigencias de la argumentación autónoma en espacios especializados, como el parlamento o un tribunal constitucional ${ }^{63}$. Pero ningún sistema político real ofrece una solución ideal. Por eso es necesario preguntar cómo mejorar el sistema político desde la perspectiva de la argumentación autónoma.

Al menos por razones analíticas, es útil separar las distintas operaciones argumentativas y asignarlas a instituciones especializadas para tales operaciones. La idea es la de una división de tareas según el tipo de operación normativa. En este sentido, Kant sugirió una división de poderes según los elementos del silogismo ${ }^{64}$. Pero cuando el sistema político -incluso la justicia- no opera según el modo del silogismo, sino que trata de establecer un orden normativo sobre la base de intereses y opiniones conflictivas, el sistema institucional debe representar las operaciones requeridas para la definición, el balance y la coordinación de los argumentos normativos basados en intereses y opiniones divergentes de los agentes autónomos.

Entonces necesitamos instituciones para

- identificar los argumentos en juego y evaluar su legitimidad y relevancia;

- formar normas generales basados en la ponderación de los argumentos;

${ }^{62}$ Cfr. el análisis de Gargarella, R., The Scepter of Reason, Dordrecht/Boston/ Londres, Kluwer, 2000, pág. 95 y ss.

${ }^{63}$ Véase la tesis de Rawls que la Corte Suprema es la ejemplificación de la razón pública, Rawls, J., Political Liberalism, Nueva York, Columbia University Press, 1996, pág. 231.

${ }^{64}$ Kant, op. cit., n. ${ }^{\circ} 2$ 2, $§ 45$ A 165/B 195, AA 6, 313. Kant sostenía que esto realizará el principio de la libertad. 
- juzgar la solidez de las diversas propuestas respecto de qué ha de ser considerado como norma vinculante común.

Más allá de estas funciones normativas queda la función de especificar cuáles son las normas objetivamente válidas en un sistema jurídico-político. Esto es la tarea tradicional de la justicia.

También queda la posibilidad de determinar normas vinculantes por autoridad, en particular en caso de que no sea posible establecer normas vinculantes de manera argumentativa. Sin embargo, tal autoridad requiere legitimación argumentativa, así que presenta un problema de justificación en sí misma, por lo que no puede ser considerada como una forma de justificación independiente.

La visión tradicional del sistema político es que las normas están establecidas de manera autoritativa por el parlamento o el gobierno, y que la justicia debe determinar y aplicar las normas objetivamente válidas en el sistema jurídico. Este panorama cambia cuando se considera las normas establecidas de manera argumentativa. La argumentación no puede reemplazar la autoridad legislativa. Pero es un factor importante en el sistema jurídico-político según las concepciones de la democracia deliberativa, y además, en cuanto los argumentos se basan en la Constitución, la exigencia de argumentar afecta también las instituciones legislativas (parlamentos, gobiernos y cortes). Además, la justicia no está limitada a la determinación de normas objetivamente válidas sino que tiene también una función creativa. Esto no significa que se desvanece la función de la justicia de determinar el derecho existente. Pero tiene o puede tener otra función con respecto a la fundamentación argumentativa de las normas.

\section{1. Las exigencias argumentativas}

\section{1.1. Identificar los argumentos relevantes}

Los argumentos normativos están basados en primer lugar en los intereses de los agentes autónomos. También sus convicciones y reclamos acerca de qué norma debe ser válida constituyen argumentos para ponderar con otros argumentos. En el ámbito del derecho entran argumentos basados en normas constitucionales o legales. Pero aún tales normas tratan de proteger algunos intereses de los ciudadanos. 
Para determinar los argumentos basados en intereses de los ciudadanos hay varias posibilidades:

- La participación directa de los agentes autónomos en la toma de decisiones.

- La expresión de intereses, opiniones y argumentos por los agentes mismos frente a los que tienen que tomar decisiones.

- Informaciones indirectas basadas en discusiones públicas o estadísticas o relatos de vida, etc.

Con respecto a los argumentos jurídicos, el discurso jurídico es la fuente de las informaciones relevantes.

\section{1.2. Ponderación y formación de normas generales}

La formación de las normas generales requiere ponderaciones de los diversos argumentos en colisión. Esto incluye varias exigencias. Son necesarias para la fundamentación de la validez definitiva de una norma ${ }^{65}$,

- la consideración de todos los argumentos relevantes,

- la consistencia de la fundamentación y del resultado ponderativo,

- la corrección de las premisas empíricas empleadas,

- la corrección de la determinación de los grados de restricción de los intereses involucrados,

- la coherencia de la ponderación con respecto al peso relativo de argumentos,

- la reflexión intersubjetiva acerca de la pregunta sobre cuál sea la norma adecuada para la situación de conflicto entre diversas opiniones normativas, la cual incluye,

- la igual consideración de concepciones normativas de cada sujeto autónomo.

${ }^{65}$ Para algunos de estos criterios véase Alexy, op. cit., n. ${ }^{\circ}$ 5; Bernal Pulido, C., "The Structure and the Limits of Balancing", ARSP-Beiheft, 97, 2004, págs. 79-84. 


\section{1.3. Juzgar la adecuación como norma vinculante}

La norma vinculante debe establecerse como resultado de un proceso de reflexión intersubjetivo. Como exigencia procedimental la necesidad de tal reflexión ya figura entre las condiciones de una ponderación correcta. Sin embargo, más allá de esta exigencia procedimental, es necesario determinar el resultado de tal reflexión. Alguien debe constatar si hay resultado, y cuál es.

El punto central es la exigencia de considerar igualmente todas las posiciones normativas en conflicto. Esto requiere, distanciarse de las propias convicciones normativas, y preguntarse cuál norma debe ser reconocida como definitivamente válida en la situación de conflicto. Esto es una forma de imparcialidad frente a las diversas posiciones, aunque dentro de una concepción normativa de un individuo autónomo. Es un juicio normativo, no una mera descripción de un resultado de la argumentación.

\section{2. La adecuación de las instituciones tradicionales del Estado constitucional-democrático}

La tripartición entre identificar argumentos, formar normas generales y determinar su validez objetiva sugiere una atribución de estas tareas a las instituciones ejecutivas, legislativas, y judicativas, respectivamente. Sin embargo, esto suena demasiado fácil. La pregunta es para cuáles funciones argumentativas los parlamentos, los gobiernos y la justicia están mejor calificados.

A este respecto, quiero defender las siguientes tesis:

(1) El parlamento es adecuado para identificar argumentos, pero no es igualmente adecuado para ponderarlos y para juzgar su adecuación como norma vinculante común.

(2) Las instituciones gubernamentales pueden ayudar en la formación de argumentos y son o pueden estar capacitadas para ponderarlos. Pero no pueden juzgar su adecuación como normas vinculantes comunes.

(3) Las instituciones judiciales pueden identificar argumentos de manera indirecta. Pueden ponderarlos, como otros órganos también. Pero su característica particular es controlar las pon- 
deraciones de otros órganos. Además, pueden juzgar la adecuación de las normas como normas vinculantes comunes.

\section{2.1. El parlamento}

El parlamento parecería el lugar adecuado para llegar a la información relevante para las decisiones políticas. En tanto que una democracia directa no parece viable en sociedades complejas, el sistema parlamentario permite el mejor acceso de los ciudadanos a las instituciones políticas y de los políticos a los ciudadanos. Además, la idea del debate parlamentario como un proceso de argumentación sugiere que el parlamento es el mejor lugar para deliberaciones sobre asuntos normativos. Sin embargo, esta idea no siempre se corresponde con la realidad institucional ${ }^{66}$.

El parlamento tiene problemas con respecto a la ponderación y la reflexión intersubjetiva ${ }^{67}$. La ponderación es una forma de argumentación restringida por varias exigencias de racionalidad. Aunque cualquier agente autónomo puede ponderar argumentos, no es claro que los políticos estén mejor calificados para hacer una ponderación racional.

Aún más, la exigencia de dar la misma consideración a todos los agentes autónomos enfrenta un problema estructural en el ámbito parlamentario ${ }^{68}$. Los legisladores tienen varios objetivos que pueden entrar en conflicto con la exigencia de una ponderación racional y equilibrada. Deben buscar mayorías. Si es necesario, van a prestar más

${ }^{66}$ Véase Becker, M./Oliver-Lalana, D./Sieckmann, J., "La producción del derecho: esbozo de un análisis normativo de la argumentación parlamentaria", en: Cardinaux, N./Clérico, L./D'Auria, A. (coord.), Las razones de la producción del derecho. Argumentación constitucional, argumentación parlamentaria y argumentación en la selección de jueces, Buenos Aires, Fac. de Derecho, 2006, págs. 108-109.

${ }^{67}$ Para un análisis a este respecto véase Sieckmann, J., «La racionalidad del debate parlamentario: un análisis del debate sobre la importación de células madre en el Parlamento Federal alemán", en: Cardinaux, N./Clérico, L./D'Auria, A. (coord.), Las razones de la producción del derecho. Argumentación constitucional, argumentación parlamentaria y argumentación en la selección de jueces, Buenos Aires, Fac. de Derecho, 2006, págs. 157-166.

${ }^{68}$ Véase también Sieckmann, J., "Argumentation und demokratische Legiti-mation", en: Sieckmann, J. (coord.), Argumentation und politische Legitimation, Baden-Baden, Nomos, 2006, págs. 64 y 66. 
atención a ciertos grupos que a otros. Además, pueden descuidar intereses de aquellos que de ninguna manera van a apoyar sus proyectos u objetivos. Otro objetivo del legislador es su carrera política. Debe cumplir con lo que demandan aquellos de quienes depende, sean sus colegas, su partido o los electores de su distrito electoral. Esto también puede influir sus decisiones y colisionar con la exigencia de una ponderación racional.

Entonces existen características estructurales del ámbito parlamentario que ponen en duda la adecuación del parlamento para ponderaciones racionales y equilibradas. Existe un conflicto entre el valor de hacer las ponderaciones por uno mismo, o al menos por sus representantes elegidos, y las exigencias de ponderar de manera racional, imparcial y equilibrada. Este conflicto admite dos soluciones: mejorar el proceso parlamentario en cuanto su calidad argumentativa, o atribuir la tarea de la ponderación a otra institución mejor calificada.

\section{2.2. El poder ejecutivo}

En los sistemas democráticos actuales, el poder ejecutivo tiene un rol dominante, incluso en la formación de proyectos legislativos. Esto constituye un problema grave para la democracia representativa y muchas veces ha sido criticado. Sin embargo, debe considerarse si el poder ejecutivo puede estar mejor calificado para hacer ponderaciones racionales y equilibradas que el parlamento.

Las ponderaciones pueden necesitar operaciones argumentativas bien complejas. Puede ser que en el ejecutivo se encuentren mejores cualidades debido a las competencias materiales de los ministerios. Puede interpretarse que la influencia del gobierno en la preparación de proyectos legislativos podría tener cierta racionalidad según las exigencias de legitimación argumentativa de las normas ${ }^{69}$.

Sin embargo, como en el caso del parlamento, el poder ejecutivo tiene la necesidad de buscar mayorías. Esto no favorece la imparciali-

${ }^{69}$ Esta linea de argumentación puede encontrarse también en la discusión de la legitimación de las decisiones de la Unión Europea, que tienen prioridad sobre las decisiones de las instituciones gubernamentales o administrativas nacionales. La idea de la legitimación por los resultados («output legitimation») sugiere que lo que importa es la capacidad de lograr buenos resultados. 
dad de la decisión. Por eso, una cierta independencia de los ministerios de las influencias políticas parece adecuada para realizar ponderaciones racionales e imparciales.

Puede objetarse que la determinación de normas generales deba ser tarea central del parlamento. Esta objeción tiene un punto correcto con respecto de la determinación autoritativa de las normas. Para esto, la legitimación democrática del parlamento es importante. Sin embargo, cuando analizamos la legitimación de las normas como resultados de procesos de ponderación y reflexión intersubjetiva, no es claro que el parlamento sea la institución mejor calificada ${ }^{70}$.

En favor del parlamento puede argumentarse que la misma competencia material que tiene la burocracia ministerial puede crearse en el ámbito del parlamento. En la realidad de un sistema parlamentario dominado, por un lado, por los partidos políticos y, por otro lado, por el gobierno, es una cuestión abierta quién está en la mejor posición de manejar procesos de argumentación con cierto grado de complejidad.

\section{2.3. La justicia}

La justicia está predestinada para realizar decisiones imparciales que satisfagan exigencias técnicas de las ponderaciones racionales. La estructura de la argumentación autónoma parece mejor preservada en procedimientos jurídicos que en los plenamente políticos ${ }^{71}$. Por eso, la gran influencia de los tribunales y cortes constitucionales en los Estados constitucionales-democráticos tiene al menos cierta justificación. ${ }^{72}$

Sin embargo, esta tesis tiene presupuestos que no se pueden tomar por dados en la realidad institucional. La independencia de la justicia implica que es difícil controlarla. El potencial de decisiones impar-

${ }^{70}$ Con esto se presupone que algunas decisiones pueden justificarse de manera argumentativa y otras son meramente decisiones autoritativas. Esta contraposición es problemática. Sin embargo, si se acepta la idea de la legitimación argumentativa y, por otro lado, los límites de esta forma de legitimación, parece inevitable distinguir entre decisiones que pueden mostrarse como correctas por medio de una argumentación y otras que no tienen criterio de corrección.

${ }^{71}$ Véase también Rawls, op. cit., n. ${ }^{\circ} 63$.

72 Otro argumento es que los fallos jurídicos promueven la deliberación pública. Véase Gargarella, op. cit., n. ${ }^{\circ}$ 62, pág. 114. 
ciales no garantiza que las decisiones judiciales son de hecho imparciales. La legitimación tradicional de la justicia se fundamenta en el conocimiento del derecho, y no en la mejor capacidad de ponderar y reflexionar sobre posiciones normativas en conflicto. Tampoco la formación jurídica está orientada hacia el desarrollo de esta capacidad. Sin embargo, la justicia está en una posición privilegiada para realizar una legitimación argumentativa de las normas.

Un argumento adicional en favor de las competencias decisivas de la justicia constitucional se sigue de la tesis de que un órgano solamente debe tener el poder para tomar determinaciones definitivas cuando se encuentra en una posición de evaluar y controlar el total del proceso argumentativo que legitima una norma. Cuando un caso llega a la justicia, en general ya se trata de problemas de la aplicación de una norma. La justicia se encuentra en una posición de un control ex post. Esto significa que puede haber información disponible para las cortes que el legislador no tenía. Y en tanto no se entienda al control de constitucionalidad de las leyes como un reproche frente al parlamento, sino como tema de la legitimidad de las leyes, esta ventaja de las cortes es relevante.

\section{Conclusión}

En fin, hemos visto una concepción de la autonomía que permite resolver la paradoja de la autonomía, es decir, cómo agentes pueden verse limitados por normas cuya validez depende de la aceptación por los agentes mismos, que la justificación de normas como vinculantes requiere procesos de argumentación autónoma, y que la legitimación democrática resulta de la institucionalización de tales procesos de argumentación autónoma en el sistema político. La autonomía consiste en formar juicios normativos sobre la base de la ponderación de argumentos normativos. La argumentación autónoma es un proceso en que agentes introducen libremente argumentos normativos y juicios normativos y tratan de llegar a normas comunes a través de un proceso de reflexión intersubjetiva. Cuando de tales procesos resulta una convergencia razonable acerca de la validez de ciertas normas, es legítimo reclamar tales normas como vinculantes. La tarea de la democracia es crear un sistema político que realice las exigencias de la argumentación autónoma. Esto requiere al menos permitir la par- 
ticipación de todos los agentes autónomos en los procesos políticos y orientar estos procesos por el objetivo de encontrar una convergencia razonable acerca de las decisiones normativas y de las normas establecidas por ellas. Sin embargo, desarrollar las implicancias para el sistema político excede los alcances de este ensayo.

\section{Bibliografía}

Alchourrón, C. E. y Bulygin, E., Normative Systems, Vienna, Springer, 1971.

Alexy, R., Teoría de la argumentación jurídica, Tr. de M. Atienza, Madrid, Centro de Estudios Constitucionales, 1989.

Alexy, R., „Diskurstheorie und Menschenrechte“, en Alexy, R., Recht, Vernunft, Diskurs, Frankfurt a.M.: Suhrkamp, 1995.

Alexy, R., Teoría de los derechos fundamentales, 3a ed., Madrid, 2008.

Alexy, R., "Ley fundamental y teoría del discurso", en id., La construcción de los derechos fundamentales, Buenos Aires: Ad Hoc, 2010.

Apel, K.-O., Transformation der Philosophie, t. 2, Frankfurt/M.: Suhrkamp, 1973.

Baumann, P., Die Autonomie der Person, Paderborn, Mentis, 2001.

Beck, L.W., A Commentary on Kant's Critique of Practical Reason, Chicago/London, Chicago University Press, 1960.

Becker, M.; Oliver-Lalana, D. y Sieckmann, J., "La producción del derecho: esbozo de un análisis normativo de la argumentación parlamentaria", en Cardinaux, N.; Clérico, L. y D'Auria, A. (coords.), Las razones de la producción del derecho. Argumentación constitucional, argumentación parlamentaria y argumentación en la selección de jueces, Buenos Aires, Fac. de Derecho, 2006.

Bernal Pulido, C., "The Structure and the Limits of Balancing", ARSP-Beiheft, n. ${ }^{\circ}$ 97, 2004.

Bittner, R., Moralisches Gebot oder Autonomie?, Freiburg/München, Alber, 1983.

Brandom, R., Making it Explicit. Reasoning, Representing, and Discursive Commitment, Cambridge (Mass.)-London, Harvard University. Press, 1994.

Dworkin, R., Law's Empire, London, Fontana, 1986.

Gargarella, R., The Scepter of Reason, Dordrecht-Boston-London: Kluwer, 2000. 
Habermas, J., Erläuterungen zur Diskursethik, Frankfurt/M., Suhrkamp, 1991.

Habermas, J., Between Facts and Norms, Cambridge (Mass.), MIT Press, 1996 (orig.: Faktizität und Geltung, 4a ed., Frankfurt a.M.,Suhrkamp, 1994).

Habermas, J., The Inclusion of the Other, Cambridge (Mass.), MIT Press, 1998 (orig.: Die Einbeziehung des Anderen, Frankfurt a.M., Suhrkamp, 1996).

Hohfeld, W. N., Fundamental Legal Conceptions as Applied in Legal Reasoning and Other Legal Essays, New Haven, Yale University Press, 1923.

Hurley, S., Natural Reasons, Oxford-New York, Oxford University Press, 1989.

Iosa, J., "Concepciones de la autonomía", Filosofía Social e Teoría do Direito, 2010. Iosa, J., "Wolff entre autoridad y autonomía", Cuadernos de Filosofia del Derecho, n. ${ }^{\circ}$ 33, 2010.

Iosa, J., "La estructura del conflicto entre autoridad y autonomía", Análisis e diritto, 2011.

Kain, P., "Self legislation in Kant's Moral Philosophy", Archiv für Geschichte der Philosophie, n. ${ }^{\circ}$ 83, 2004.

Kamp, G., Logik und Deontik, Paderborn, Mentis, 2001.

Kant, I., Grundlegung zur Metaphysik der Sitten, Akademieausgabe (AA), Berlin, 1911, t. 4.

Kant, I., Kritik der praktischen Vernunft, Akademieausgabe (AA), Berlin 1913, t. 5.

Kant, I., Metaphysik der Sitten, Einleitung in die Rechtslehre (1797/98), Akademieausgabe (AA), Berlin, 1914, t. 6.

Kaufmann, M., Rechtsphilosophie, Freiburg-München, Alber, 1996.

Korsgaard, C., "The Authority of Reflection", en Korsgaard, C. M., The Sources of Normativity, Cambridge, Cambridge University Press, 1996.

Mele, A. R., Autonomous Agents. From Self-Control to Autonomy, Oxford, Oxford University Press, 1995.

Nagl-Docetal, H., "Autonomie zwischen Selbstbestimmung und Selbstgesetzgebung", en: Pauer-Studer, H. y Nagl-Docetal, H. (eds), Freiheit, Gleichheit, Autonomie, Wien-Berlin, Oldenbourg-Akademie Verlag, 2003. 
Nino, C. S., Ética y derechos humanos. Un ensayo de fundamentación, Barcelona, Ariel, 1989.

Nino, C. S., The Ethics of Human Rights, Oxford, Oxford University Press, 1991.

Nino, C. S., The Constitution of Deliberative Democracy, New Haven-London, Yale University Press, 1996.

Paton, H.J., The Categorical Imperative. A Study in Kant's Moral Philosophy, 3ed., London, Hutchinson, 1958.

Patzig, G., "Philosophische Bemerkungen zum Begriff der Autonomie", en Patzig, G., Gesammelte Schriften I: Grundlagen der Ethik, Göttingen, Wallstein Verlag, 1994.

Rawls, J., A Theory of Justice, Cambridge, Harvard University Press, 1971.

Rawls, J., Political Liberalism, New York, Columbia University Press, 1996.

Raz, J., The Morality of Freedom, Oxford, Clarendon, 1986.

Reath, R., Agency and Autonomy in Kant's Moral Theory. Selected Essays, Oxford, Clarendon Press, 2006.

Rousseau, J. J., Contrat Social, Amsterdam, 1762.

Schneewind, J., The Invention of Autonomy, New York, Cambridge University Press, 1998.

Sieckmann, J., "Legal System and Practical Reason", Ratio Juris, 5, 1992.

Sieckmann, J., "Cultural Pluralism and the Idea of Human Rights", en: Soeteman, A. (coord.), Pluralism and Law, Dordrecht, Kluwer, 2001.

Sieckmann, J., "On the Tension Between Moral Autonomy and Rational Justification", Ratio Juris, 16, 2003.

Sieckmann, J., "Autonome Abwägung", ARSP 90, 2004.

Sieckmann, J., "Argumentation und demokratische Legitimation", en: Sieckmann, J. (coord.), Argumentation und politische Legitimation, Baden-Baden: Nomos, 2006.

Sieckmann, J., "La racionalidad del debate parlamentario: un análisis del debate sobre la importación de células madre en el Parlamento Federal alemán", en Cardinaux, N.; Clérico, L. y D'Auria, A. (coord.), Las razones de la producción del derecho. Argumentación constitucional, argumentación parlamentaria y argumentación en la selección de jueces, Buenos Aires, Fac. de Derecho, 2006. 
Sieckmann, J., "The Concept of Autonomy", en Gizbert-Studnicki, T. y Stelmach, J. (eds.), Law and Legal Cultures in the 21st Century: Diversity and Unity, Cracow, Oficina-Kluwers, 2007.

Sieckmann, J., The Logic of Autonomy, Oxford-Portland, Hart Publishing, 2012.

Spector, H., Autonomy and Rights, Oxford, Oxford University Press, 1994.

Stuhlmann-Laeisz, R., Das Sein-Sollen-Problem, Stuttgart-Bad Cannstatt, Frommann-holzboog, 1983.

Tugendhat, E., Vorlesungen über Ethik, Frankfurt a.M., Suhrkamp, 1993.

v. Wright, G. H., Norm and Action, London-New York, Routledge \& Kegan Paul, 1963.

Wildt, A., Autonomie und Anerkennung. Hegels Moralitätskritik im Lichte seiner Fichte-Rezeption, Stuttgart, Klett-Cotta, 1982.

Wolff, R. P., In Defense of Anarchism, Berkeley, University of California Press, 1973.

Wood, A., Kantian Ethics, Cambridge, Cambridge University Press, 2008. 